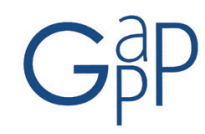

GESTIÓN Y ANÁLISIS DE POLÍTICAS PÚBLICAS, Nueva Época, nº 12 julio-diciembre 2014 ISSN: 1989-8991

DOI: http://dx.doi.org/10.24965/gapp.voi12.10205

\title{
A la búsqueda del equilibrio entre transparencia administrativa y protección de datos. Primeros desarrollos en el ámbito municipal
}

\author{
Julio César Tejedor Bielsa \\ Profesor titular de Derecho Administrativo de la Universidad de Zaragoza \\ tejedori@unizar.es
}

Recibido: 29 de octubre 2014

Aceptado: 25 de noviembre 2014

\begin{abstract}
Resumen
El estudio se centra en la búsqueda del equilibrio entre transparencia administrativa y protección de datos tras la Ley 19/2013, de 9 de diciembre, de transparencia, acceso a la información publica y buen gobierno. La tensión existente entre el interés público que exige la máxima transparencia y accesibilidad a la información pública y los intereses particulares en la protección de los datos personales debe resolverse salvaguardando en lo posible uno y otros. En los últimos años, culminada la aprobación de la nueva normativa básica estatal, las Comunidades Autónomas están dotándose rápidamente de normativa legal en materia de transparencia. Pero también habrán de hacerlo los municipios. En ese contexto Zaragoza ha venido desarrollando una intensa actividad de modernización impulsando la administración electrónica y, de forma pionera la transparencia. La reciente aprobación de la ordenanza municipal, que desarrolla e impulsa la aplicación de la normativa básica, constituye un magnífico ejemplo para contrastar la eficacia de las respuestas legales a la búsqueda del equilibrio entre transparencia y privacidad.
\end{abstract}

Palabras clave

Derecho administrativo, gobierno abierto, información pública protección de datos, transparencia.

\section{Searching the balance between administrative transparency and data protection. First developments in municipalities}

\section{Abstract}

The study focuses on the search of the balance between administrative transparency and data protection after the Law 19/2013, of December 9, of transparency, access to the public information and good governance. The existing tension between the public interest that demands the maximum transparency and accessibility to the public information and the particular interests in the protection of the personal information must be solved safeguarding as much as possible the one and others. Recently, reached the approval of the new basic state regulation, the Autonomous Communities have approved quickly legal regulation about transparency. But also the municipalities must do it. In this context Saragossa has come developing an intense activity of modernization stimulating the electronic administration and the new pioneering ordinance of transparency. The recent approval of the ordinance, which develops and stimulates the application of the basic regulation, constitutes a magnificent example to check the efficacy of the legal answers to the search of the balance between transparency and privacy.

Keywords

Administrative law, open government, public information, data protection, transparency. 


\title{
SUMARIO
}

\begin{abstract}
I. ADMINISTRACIÓN ELECTRÓNICA, TRANSPARENCIA Y PROTECCIÓN DE DATOS.-II. CONCEPTO DE INFORMACIÓN PÚBLICA. LÍMITES: 1. Presunción de publicidad y protección de datos; 2 . Limitaciones a la publicidad y criterios de ponderación.-III. UN NUEVO MARCO DE RELACIÓN PARA LA PROTECCIÓN DE DATOS PERSONALES Y LA TRANSPARENCIA ADMINISTRATIVA: 1. Contenido y régimen jurídico básico; 2. La información previa y la necesidad de consentimiento del titular de los datos para el tratamiento y otras garantías legales; 3. Los datos personales y la administración electrónica. Metadatos complementarios sobre datos personales. Implicaciones para la ponderación y disociación; 4. La articulación del derecho fundamental a la protección de datos con la transparencia y acceso público a la información en la pionera Ordenanza de Zaragoza: A) La primera propuesta de articulación entre transparencia y protección de datos en 2013 en el marco normativo anterior a la Ley de Transparencia; B) La adecuación de la propuesta de 2013 a la Ley de Transparencia y su sustancial modificación en la ordenanza finalmente aprobada.-BIBLIOGRAFÍA
\end{abstract}

\section{ADMINISTRACIÓN ELECTRÓNICA, TRANSPARENCIA Y PROTECCIÓN DE DATOS}

La transparencia ha emergido en los últimos años como uno de los más relevantes principios vinculados a la modernización administrativa y a la mejora de la calidad democrática, la participación ciudadana y los procedimientos de control de nuestras instituciones. De la tradicional perspectiva de la organización administrativa, con la regulación del régimen de publicidad de los órganos colegiados, y del derecho de acceso a archivos y registros, regulado restrictivamente en la legislación de régimen jurídico de las administraciones públicas, se está pasando rápidamente a un entorno novedoso, en el que la transparencia de las instituciones públicas y algunas personas o entidades que se relacionan con ellas, reutilización de la información, el control social de la administración y el buen gobierno se ubican en primer plano. Y en ese entorno la búsqueda del equilibrio se esta revelando como objetivo esencial, como había ya apuntado la doctrina, porque ni transparencia ni protección de datos son absolutos (PIÑAR, 2010: 82-101) y porque el avance tecnológico, desde la perspectiva del incremento de la capacidad de generación y tratamiento de datos y el desarrollo de las redes incrementan notablemente los riesgos (BALLESTEROS, 2006: 41-42).

Limitándonos a las más relevantes referencias de ámbito europeo no pueden dejar de mencionarse las normas emanadas de las Unión Europea, por un lado, y del Consejo de Europa, por otro'. La Unión Europea reguló el acceso público a los documentos del Parlamento Europeo, del Consejo y de la Comisión Europea mediante el Reglamento 1049/2001, de 30 de mayo de 2001, cuya revisión, en curso por cierto, parece estar atravesando dificultades atendiendo a la Resolución del Parlamento Europeo, de 12 de junio de 2013, sobre el punto muerto en la revisión del Reglamento (CE) 1049/2001 [2013/2637(RSP)]. El Reglamento desarrolla fundamentalmente el acceso mediante solicitud, delimitando el ámbito documental accesible mediante un amplia regulación de las excepciones de acceso, previendo el silencio administrativo negativo ante la falta de respuesta e imponiendo ciertas reglas sobre publicidad, bien es cierto que de alcance notablemente limitado, pues "las instituciones permitirán el acceso directo del público a los documentos, en la medida de lo posible” (art. 12.1 Reglamento), "se debería facilitar el acceso directo a los documentos legislativos" (art. 12.2 Reglamento), "siempre que sea posible, se debería facilitar el acceso directo a otros documentos, en particular los relativos a la elaboración de políticas o estrategias" (art. 12.3 Reglamento). En cualquier caso, el Reglamento incluye entre los supuestos en que deberá denegarse el acceso a un documento aquellos en que la divulgación suponga un perjuicio para la protección de la intimidad e integridad de la persona, en particular de conformidad con la legislación comunitaria sobre protección de los datos personales [art. 4.1.b) Reglamento].

Por su parte, el Consejo de Europa promovió el Convenio sobre el acceso a los documentos públicos, de 18 de junio de 2009 (en adelante se cita como Convenio), aún no ratificado por España, en el cual, sin perjuicio alguno de las leyes y regulaciones propias de cada Estado y de los tratados internacionales que reconocen un derecho más amplio de acceso a los documentos públicos (art. 1.1 Convenio), se establecen unas reglas mínimas de garantías de acceso a documentos públicos, que tienen presentes las normas sobre protección de datos personales, y se centran en el acceso bajo petición, limitándose a prever la publicidad activa por propia iniciativa de las autoridades públicas y cuando sea conveniente, para promover la transparencia y la eficacia de la administración y para fomentar la participación informada del público en materias de interés general (art. 10 Convenio). Conviene advertir, por lo demás, que el Convenio también prevé el efecto denegatorio del silencio ante las solicitudes de acceso, por cuan-

\footnotetext{
$1 \quad$ Para una exposición más amplia de los antecedentes comparados FERNÁNDEZ y PÉREZ, 2014: 19 -24.
} 
to, aun cuando no lo establece al regular la tramitación de las solicitudes de acceso, que concretarán las normas nacionales, así se desprende de la regulación del procedimiento de reclamación, conforme a la cual "un solicitante que pida un documento oficial y cuyo acceso le ha sido denegado expresamente o implícitamente, parcialmente o por completo, tendrá acceso a un procedimiento de reclamación antes de la apelación ante un tribunal u otra institución independiente e imparcial establecida por la ley" (art. 8.1 Convenio).

Las normas sucintamente comentadas están llamadas a operar en un contexto de profunda transformación del funcionamiento de la administración, y de su proyección pública, gracias a las nuevas tecnologías de la información y la comunicación, auténtica piedra angular del proceso, y a la implantación de la administración electrónica, en el marco previsto en la Ley 11/2007, de 22 de junio, de acceso electrónico de los ciudadanos a los servicios públicos (en adelante LAESP) y sus disposiciones de desarrollo. De este proceso surgió, en el ámbito del Ayuntamiento de Zaragoza, que ha desarrollado una intensa actividad en este tema ${ }^{2}$, la Ordenanza de Administración electrónica de 21 de abril de 2010 (en adelante OAE), fundamental en la materia que nos ocupa. Este nuevo entorno, no obstante, suscita también nuevos riesgos y, entre ellos, de forma destacada, los que pudieran poner en peligro el derecho fundamental a la protección de los datos de carácter personal. Por ello la OAE incorporó entre los derechos de la ciudadanía, adicionales a los establecidos en el artículo 6 LAESP, que prevé el derecho "a la garantía de la seguridad y confidencialidad de los datos que figuren en los ficheros, sistemas y aplicaciones de las Administraciones Públicas" [art. 6.2.j) LAESP], el "derecho a la protección de los datos personales y, en especial, a que la información personal no pueda ser destinada a una finalidad distinta de aquella para la cual se consintió su tratamiento" [art. 5.1c) OAE]. Desde esa perspectiva garantista, se estableció un riguroso régimen al que quedaron sujetas las administraciones públicas para recabar y obtener el consentimiento de los ciudadanos para el tratamiento, la utilización, la obtención o la cesión de sus datos personales, sujeto a plazo de caducidad de diez años, nunca genérico, y restrictivo, al configurarse como excepcional, en lo que se refiere a la comunicación de datos a entidades privadas, sujeto a "causa justificada" (art. 7 OAE).

Hasta la reciente Ley 19/2013, de 9 de diciembre, de transparencia, acceso a la información publica y buen gobierno (en adelante LTAIPBG), la fundamental normativa de referencia respecto del acceso a archivos y registros ha venido siendo, sobre la base de lo establecido en el artículo 105.b) de la Constitución, la prevista en los artículos 35.h) y 37 de la Ley 30/1992, de 26 de noviembre, de régimen jurídico de las administraciones públicas y del procedimiento administrativo común (en adelante LAP), ambos modificados por la LTAIPBG hasta el punto de incorporar hoy día una mera remisión a la misma, manteniendo en todo caso la regulación del acceso a los expedientes relativos a procedimientos en curso limitado a los interesados [art. 35.a) LAP]3. No obstante, resulta de interés analizar la regulación hoy derogada, útil como contraste hermenéutico con la resultante de la nueva LTAIPBG. El art. 35.h) establecía el derecho de los ciudadanos, en sus relaciones con las administraciones públicas, "al acceso a los registros y archivos de las Administraciones Públicas en los términos previstos en la Constitución y en ésta u otras Leyes", dedicándose el art. 37 a la regulación de dicho derecho de acceso en términos restrictivos, desde la perspectiva de la transparencia administrativa, que fueron criticados doctrinalmente por ello4.

Ciertamente, el análisis del art. 37 LAP ponía claramente de manifiesto su ánimo restrictivo tanto desde una perspectiva subjetiva como objetiva ${ }^{5}$. Así, aun cuando inicialmente se atribuía el derecho de acceso genéricamente a los ciudadanos (al respecto, por todas, vid. la Sentencia del Tribunal Supremo de 30 de marzo de 1999, Arz. 3246/1999), que eran los titulares del derecho de acceso, cuando los documentos contengan datos referentes a la intimidad de las personas eran sólo éstas las que podían acceder, mientras que en los casos en que los docu-

2 El caso del municipio de Zaragoza, al que me referiré a lo largo del presente trabajo, resulta útil para analizar el proceso de desarrollo de la administración electrónica, la transparencia administrativa y la reutilización de la información, todo ello en relación con las exigencias de la normativa de protección de datos. A la normativa aprobada por dicho Ayuntamiento en estas materias, como la citada en texto OAE (https://www.zaragoza.es/ciudad/normativa/detalle_Normativa?id=922, consulta: 16 de octubre de 2014), y la pionera Ordenanza sobre transparencia y libre acceso a la información aprobada el 1 de abril de 2014 (https://www.zaragoza.es/ciudad/normativa/detalle Normativa?id=3983, consulta: 16 de octubre de 2014; OTLAI en adelante) realizaré diversas referencias a lo largo de este trabajo. También de interés, por la influencia que puede tener en el mundo local, resulta la Ordenanza tipo de transparencia, acceso a la información y reutilización aprobada por la Junta de Gobierno de la Federación Española de Municipios y Provincias el 27 de mayo de 2014 (en adelante OtTAIR).

3 Dejando al margen el régimen vigente en materia de acceso a información ambiental, derivado de la Directiva 2003/4/CE, de acceso a la información en materia de medio ambiente y la Ley 27/2006, de 18 de julio, por la que se regulan los derechos de acceso a la información, participación pública y de acceso a la justicia en materia de medio ambiente. Como ha destacado la doctrina no deja de resultar sorprendente esta dualidad de regímenes jurídicos (FERNÁNDEZ y PÉREZ , 2014: 30).

4 FERNÁNDEZ y PÉREZ, 2014: 29, por ejemplo, afirman categóricamente que "la regulación del derecho contenida en la LRJAPAC era marcadamente restrictiva y, en ocasiones, ininteligible, aparentemente más preocupada en ofrecer obstáculos y trabas al acceso que en garantizarlo, a lo cual debe añadirse su parquedad en materia de procedimiento y a la completa ausencia de garantías".

5 Lo que los hizo objeto de duras críticas doctrinales con tacha, incluso, de posible inconstitucionalidad. Entre los primeros PARADA, 1993: 165; POMED, 1997: 457-459 y 466-467, comentando la posición del anterior; pero tras él muchos otros como PIÑAR , 2010: 98 ; o GUICHOT, 2009: 203-204 y nota 333 . 
mentos tenían carácter nominativo sin incluir otros datos relativos a la intimidad, salvo que fuesen de carácter sancionador o disciplinario, podían acceder sus titulares y quienes acreditasen un interés legítimo y directo. Sólo esta primera perspectiva implicaba ya un notable alejamiento de lo habitual en las normas de transparencia. Por ejemplo, véanse para constatarlo los arts. 4.1 del Convenio del Consejo de Europa, que prevé que "un solicitante no podrá ser obligado a dar sus razones para tener acceso a un documento oficial" o 12 de la LTAIPBG, que atribuye el derecho de acceso, desbordando también los mínimos constitucionales, a "todas las personas", sin exclusión alguna ${ }^{6}$.

Pero también desde el punto de vista objetivo el derecho de acceso regulado en el art. 37 LAP resultaba notablemente restrictivo. En primer lugar, porque partía de una regla general conforme a la cual el acceso podía ser denegado cuando prevaleciesen razones de interés público, por intereses de terceros más dignos de protección o cuando así lo dispusiese una Ley, debiendo, en estos casos, el órgano competente dictar resolución motivada (art. 37.4 LAP). Pero además, por si tal regla fuera poco, se excluían muchos otros documentos, dejando al margen del acceso en coherencia con el antes aludido artículo 35.a) LAP todos los obrantes en procedimientos no terminados (aunque se tratase de documentos perfectamente identificables y ya concluidos), como ocurre, de forma criticable en mi opinión, con los que contienen información sobre las actuaciones del Gobierno del Estado o de las Comunidades Autónomas, en el ejercicio de sus competencias constitucionales no sujetas a Derecho Administrativo (reflejo de los actos políticos o de gobierno) o, de forma más acorde con la normativa de transparencia, con los que contienen información sobre la defensa nacional o la seguridad del Estado, los tramitados para la investigación de los delitos cuando pudiera ponerse en peligro la protección de los derechos y libertades de terceros o las necesidades de las investigaciones que se estén realizando o los relativos a las materias protegidas por el secreto comercial o industrial, los relativos a actuaciones administrativas derivadas de la política monetaria (art. 37.5 LAP).

Por lo demás, la LAP se configuraba en esta materia como ley básica general, que excluía de su ámbito, remitiendo a sus disposiciones específicas, el acceso a los archivos sometidos a la normativa sobre materias clasificadas, el acceso a documentos y expedientes que contuviesen datos sanitarios personales de los pacientes, los archivos regulados por la legislación del régimen electoral, los archivos que sirviesen a fines exclusivamente estadísticos dentro del ámbito de la función estadística pública, el Registro Civil y el Registro Central de Penados y Rebeldes y los registros de carácter público cuyo uso estuviese regulado por una Ley, el acceso a los documentos obrantes en los archivos de las Administraciones Públicas por parte de las personas que ostentasen la condición de Diputado de las Cortes Generales, Senador, miembro de una Asamblea legislativa de Comunidad Autónoma o de una Corporación Local y la consulta de fondos documentales existentes en los Archivos Históricos (que se regía, y se rige, especialmente, por los arts. 23 a 32 del Real Decreto 1708/2011, de 18 de noviembre).

Pues bien, la disposición final primera de la LTAIPBG ha dado nueva redacción a los citados artículos $35 . h$ ) y 37 LAP7 . El primero, se limita ahora a establecer el derecho de los ciudadanos, en sus relaciones con las administraciones públicas, "al acceso a la información pública, archivos y registros", mientras que el segundo prevé únicamente que "Ios ciudadanos tienen derecho a acceder a la información pública, archivos y registros en los términos y con las condiciones establecidas en la Constitución, en la Ley de Transparencia, Acceso a la Información Pública y Buen Gobierno y demás leyes que resulten de aplicación” remitiendo íntegramente la cuestión, de este modo, a la misma. Ciertamente, tan relevante modificación, unida al nuevo régimen jurídico del acceso a la información pública surgido de la aprobación de la nueva LTAIPBG, altera muy sustancialmente el contexto normativo en el

6 El artículo 30 OTLAI permite solicitar el acceso a la información pública a "cualquier persona o entidad".

7 La LTAIPBG, que no previó un régimen transitorio ni disposición derogatoria, sí mostró notable prudencia en la regulación de su entrada en vigor, tras la modificación de la disposición final novena (séptima inicialmente) del proyecto de ley a su paso por el Senado al aceptarse la enmienda número 237 del Grupo Parlamentario Popular. Así, si el proyecto de ley preveía que entraría en vigor “el día siguiente al de su publicación en el Boletín Oficial del Estado, excepto su Título I [el dedicado a la transparencia de la actividad pública], que entrará en vigor al año de dicha publicación", la LTAIPBG establece que "las disposiciones previstas en el Título II entrarán en vigor al día siguiente de su publicación en el Boletín Oficial del Estado”, “el Título Preliminar, el Título I y el Título III entrarán en vigor al año de su publicación en el Boletín Oficial del Estado" y que "los órganos de las Comunidades Autónomas y Entidades Locales dispondrán de un plazo de dos años para adaptarse a las obligaciones contenidas en esta Ley". De este modo, se diseño un proceso gradual para la puesta en práctica de la nueva normativa, del todo coherente con la complejidad técnica y organizativa que puede revestir. Aparentemente, tan solo la regulación del buen gobierno en el Título II LTAIPBG entraría en vigor de manera inmediata (al día siguiente al de su publicación en el Boletín Oficial del Estado), pero dado que la vacatio legis de un año desde dicha publicación tan sólo se refiere al Título Preliminar, el Título I y el Título III, pero no a la parte final de la nueva norma, se suscita la duda acerca de si entró esta en vigor, incluida la relevante modificación de los artículos 35 .h) y 37 LAP, a los veinte días de su publicación. A mi juicio, quedando en conflicto el interés público en la transparencia y la seguridad jurídica, ante la inconcreción legal, pudiera resultar razonable entender que, por conexión, la modificación de lo establecido en los artículos 35.h) y 37 LAP sólo habrá de considerarse vigente cuando lo esté en su integridad el nuevo régimen jurídico de acceso a la información pública. Por lo demás, el plazo de adaptación de dos años otorgado a Comunidades Autónomas y Entidades Locales en relación con las obligaciones contenidas en la LTAIPBG resulta coherente con su complejidad. Sorprende, en todo caso, que dicho plazo se limite a Comunidades Autónomas y a Entidades Locales y no alcance a otras entidades sujetas a la LTAIPBG, por razones semejantes. 
que habrían de desenvolverse las normas autonómicas y las ordenanzas de transparencia, que resulta mucho más favorable a sus avanzadas determinaciones sobre publicidad activa y libre acceso a la información pública. Sobre ello volveré más adelante.

Asimismo, debe destacarse el carácter básico de la LTAIPBG, en su mayor parte, y su carácter de norma de mínimos. Desde esta segunda perspectiva se prevé de forma expresa que "las obligaciones de transparencia contenidas en este capítulo [dedicado a la publicidad activa] se entienden sin perjuicio de la aplicación de la normativa autonómica correspondiente o de otras disposiciones específicas que prevean un régimen más amplio en materia de publicidad" (art. 5.2 LTAIPBG). La referencia a "otras disposiciones específicas" ampara la previsión de obligaciones de transparencia más exigentes establecidas mediante normas reglamentarias y, entre ellas, mediante ordenanzas, siempre en el marco de lo establecido en las leyes ${ }^{8}$. El carácter básico de la LTAIPBG, por lo demás, coherente con su amplio ámbito subjetivo de aplicación, resulta de lo establecido en su disposición final sexta, que precisa que "la presente Ley se dicta al amparo de lo dispuesto en los artículos 149.1. ${ }^{a}, 149.1 .13 .{ }^{a}$ y 149.1.18. ${ }^{a}$ de la Constitución". Únicamente se exceptúan normas organizativas dirigidas a la Administración General del Estado contenidas en el segundo párrafo del apartado 2 del artículo 6, el artículo 9, los apartados 1 y 2 del artículo 10 , del artículo 11, el apartado 2 del artículo 21, el apartado 1 del artículo 25, el Título III y la disposición adicional segunda, que, a lo sumo, podrían ser objeto de aplicación supletoria conforme a lo establecido en el artículo 149.3 de la Constitución en defecto de norma autonómica?.

En la legislación autonómica aprobada hasta el momento resulta curioso comprobar cómo difiere el tratamiento que en ella se realiza de la administración local. Así, si la normativa básica sobre transparencia, acceso a la información pública y buen gobierno incluye en su ámbito subjetivo a las entidades que integran la administración local y sus entidades instrumentales públicas o privadas (art. 2.1 LTAIPBG), no ocurre lo mismo en todas las leyes autonómicas. La normativa autonómica es de aplicación a la administración local andaluza y extremeña, pero no a la balear, gallega, navarra y riojana, que se rigen únicamente por la normativa básica estatal.

En todo caso, las referencias a la normativa internacional, comunitaria y estatal que se acaban de realizar ponen de manifiesto que, en el proceso de implementación de la administración electrónica, primero, y en el de la efectiva implantación de la transparencia y la garantía de acceso a la información pública, o su reutilización, después, resulta esencial atender a las exigencias del derecho fundamental a la protección de datos tal cual resulta de la propia normativa comunitaria europea, el artículo 18 de la Constitución y la Ley Orgánica 15/1999, de 13 de diciembre, de protección de datos de carácter personal, y en el Real Decreto 1720/2007, de 21 de diciembre, por el que se aprueba el reglamento de desarrollo de dicha Ley (en lo sucesivo se citarán como LOPD y RPD respectivamente $)^{10}$. Pero antes de abordar tales exigencias y para delimitar la zona de conflicto conviene analizar el concepto de información pública.

\section{CONCEPTO DE INFORMACIÓN PÚBLICA. LÍMITES}

\section{Presunción de publicidad y protección de datos}

La tensión existente entre la normativa de protección de datos y la de transparencia surge inevitablemente desde el momento mismo en que se delimitan los ámbitos de una y otra. Los datos protegidos y la información pública, por tanto, son los conceptos de los que ha de partirse para identificar y resolver los posibles conflictos. El concepto de información pública se define con muy notable amplitud al establecer que "se entiende por información pública los contenidos o documentos, cualquiera que sea su formato o soporte, que obren en poder de alguno de los sujetos incluidos en el ámbito de aplicación de este título y que hayan sido elaborados o adquiridos en el ejercicio de sus funciones" (art. 13 LTAIPBG), de modo que será objeto de publicidad activa "la información cuyo conocimiento sea relevante para garantizar la transparencia de su actividad relacionada con el funcionamiento y

8 COTINO, 2014: 65-70, considera que, aun siendo la LTAIPBG una norma homologable a las de nuestro entorno, sus debilidades son oportunidades para las regulaciones autonómicas y, desde la perspectiva de este trabajo, ordenanzas municipales.

9 Teniendo presente la incidencia que pudiera tener, en relación con la administración local, la competencia autonómica en esta materia. Hasta el momento cuentan con normativa legal en materia de transparencia las Comunidades Autónomas de Andalucía (Ley 1/2014, de 24 de junio, de transparencia de Andalucía), Extremadura (Ley 4/2013, de 21 de mayo, de Gobierno Abierto de Extremadura), Galicia (Ley 4/2006, de 30 de junio, de transparencia y de buenas prácticas en la Administración pública gallega), Islas Baleares (Ley 4/2011, de 31 de marzo, de la buena administración y del buen gobierno de las Illes Balears), La Rioja (Ley 3/2014, de 11 de septiembre, de transparencia y buen gobierno de La Rioja) y Navarra (Ley Foral 11/2012, de 21 de junio, de la transparencia y del gobierno abierto). La mayor parte del resto de Comunidades cuentan con anteproyectos o proyectos de ley en tramitación. Al respecto, con referencias a las bases competenciales de la normativa estatal, vid. VELASCO, 2013: 279-328 o 2014: 1-34: RUÍZ-RICO, 2014: 1-30.

10 Partiendo de una poco deseable descoordinación entre derecho de acceso y protección de datos en la LAP y la LOPD, según afirman, entre muchos otros, FERNÁNDEZ y PÉREZ, 2014: 32-34. 
control de la actuación pública" (art. 5.1 LTAIPBG)¹. Además, la LTAIPBG enuncia por bloques materiales qué ha de considerarse información pública en sus artículos 6 a 8, sobre información institucional, organizativa y de planificación; información de relevancia jurídica e información económica, presupuestaria y estadística respectivamente ${ }^{12}$.

Tan amplia definición de información pública ha de contrastarse con el concepto de datos personales protegidos. Para que se aplique la normativa de protección de datos hemos de encontrarnos ante documentos que contengan datos personales, en el sentido de la LOPD, es decir, "cualquier información concerniente a personas físicas identificadas o identificables" [art. 3.b) LOPD], que dichos datos se encuentren "registrados en soporte físico, que los haga susceptibles de tratamiento" (art. 2.1 ab initio LOPD). Pero hay que tener presente, en segundo lugar, que la normativa de protección de datos no resultará de aplicación cuando, aun conteniendo los documentos datos que pudieran considerarse datos personales, se hayan sometido previamente a un proceso de disociación, de modo que no lo serán a los efectos de la LOPD (art. 11.6 LOPD), pues, como ha señalado la Agencia Española de Protección de Datos "cuando el tratamiento se refiere únicamente a datos disociados que no permiten identificar al afectado al que los mismos se refiere no nos encontraremos ante datos de carácter personal y, en consecuencia, no estaremos dentro del ámbito descrito en el artículo 2.1 de la Ley Orgánica 15/1999" (informe 37/2010).

La OTLAI también establece una definición genérica, y sustancialmente coincidente con la anterior, precisando que "es información publica del Ayuntamiento de Zaragoza toda aquella que obre en su poder y que haya sido elaborada o adquirida en el ejercicio de sus funciones. Esta información podrá estar en soporte papel o en formato electrónico y, en este segundo caso, tener la forma de datos o de documentos electrónicos" (art. 6.1 OTLAI). Pero, además, la OTLAI establece una auténtica presunción del carácter público de la información al prever taxativamente, ahora con la cobertura que le proporciona el artículo 13 LTAIPBG, que "se presume el carácter público de la información obrante en la Administración municipal, pudiendo denegarse el acceso a la misma únicamente en los supuestos expresamente previstos por las leyes y por esta Ordenanza, y mediante resolución motivada, que podrá impugnarse en vía administrativa y judicial" (art. 3.1 OTLAI).

Frente a los tres grupos en que la LTAIPBG estructura la información pública, antes señalados, la OTLAI desarrolla siete bloques de información pública (dejando al margen la publicación de determinada información obrante en expedientes terminados y la de diarios, boletines y anuncios, que cuenta con normativa específica), en términos muy amplios, mucho más allá de los mínimos establecidos en la LTAIPBG, lo cual, sin duda, contribuirá a mejorar sustancialmente los niveles de transparencia del Ayuntamiento de Zaragoza. Tales bloques son los de información sobre normativa y actividad administrativa (art. 19 OTLAI), información sobre organización, personal y retribuciones (art. 20 OTLAI), información sobre las cuentas y el patrimonio municipales (art. 21 OTLAI), información sobre contratos y subvenciones (art. 22 OTLAI), información sobre urbanismo (art. 23 OTLAI), información sobre medio ambiente (art. 24 OTLAI) e información vinculada a la prestación de servicios y a la gestión de recursos (art. 25 OTLAI). Por lo demás, como he señalado anteriormente, la OTLAI clasifica en tres bloques la información pública, la vinculada a la transparencia, la obrante en los expedientes administrativos y la vinculada a la prestación de servicios y a la gestión de recursos (art. 6.3 OTLAI).

Conforme a lo anterior, el órgano municipal competente deberá elaborar el catálogo de información a publicar y publicarlo en su sede electrónica, indicando los distintos conjuntos de datos o documentos y, para cada uno de ellos, el órgano o servicio del que procede la información y los plazos máximos de actualización (art. 18.1 OTLAI). El catálogo, que guarda cierta semejanza con el portal de transparencia que regula el artículo 10 LTAIPBG, accesible, interoperable y reutilizable conforme al mismo, habrá de incluir toda la información sujeta a publicación, así como la que se contemple en los códigos, recomendaciones o conjuntos de indicadores propuestos por organizaciones nacionales e intencionales de reconocido prestigio en cuyo ámbito de actuación se incluyan la transparencia y el libre acceso a la información del sector publico (art. 18.2 OTLAI) ${ }^{13}$. Se comprende que, dada

11 En sentido similar, artículos 6.1 OTLAI, que considera información pública toda la que obre en poder del Ayuntamiento de Zaragoza que haya sido elaborada o adquirida en el ejercicio de sus funciones y, por remisión a la propia LTAIPBG, 8 OtTAIR.

12 La definición de la información pública en la LTAIPBG no fue objetada, en lo sustancial, por la Agencia Española de Protección de Datos. En cambio, alguna matización propuso el Consejo de Estado, en sentido limitativo, en relación con las obligaciones de transparencia de las sociedades mercantiles incluidas en el ámbito de la LTAIPBG, por ejemplo, por cuanto pueden colocarlas en situación desventajosa en el mercado de bienes y servicios, o la conveniencia de coordinar las obligaciones generales de transparencia con las sectoriales en los ámbitos de contratación del sector público, convenios o subvenciones [Informe 707/2012, c), d) y e)].

13 Ya anteriormente la OAE previó en su día la inclusión en la sede electrónica de toda aquella información sobre el Ayuntamiento y su funcionamiento que posibilite el ejercicio de los derechos políticos de la ciudadanía, ya sea a través de un mejor conocimiento de la institución, ya potenciando la transparencia de su funcionamiento (art. 21.2 OAE). Además, a juicio de los responsables de su gestión, la sede electrónica del Ayuntamiento de Zaragoza podía incluir otra información relacionada con los servicios prestados o promovidos por el Ayuntamiento que resultase de interés para la ciudadanía y, en particular, la relacionada con la salud, la cultura, la educación, los servicios sociales, el medio ambiente, los transportes, el comercio o los deportes (art. 21.3 OAE). El tablón municipal electrónico, que debía contener los edictos y anuncios, 
la amplitud de la información pública conforme a la OTLAI, se prevea la incorporación progresiva de la misma al catálogo estableciendo prioridades en función de la relevancia que, a juicio del órgano competente en la materia, tengan los diferentes datos o documentos para la ciudadanía y, en su caso, las solicitudes presentadas instando su publicación, los resultados de las consultas y encuestas que se realicen al efecto, y el numero de las solicitudes para su puesta a disposición (art. 18.3 OTLAI).

Fácilmente se constata, atendiendo a lo anterior, que la OTLAI resulta mucho más detallada, y ambiciosa en su exigencia de publicidad de la información administrativa, que la propia LTAIPBG. Sin embargo, de ello no puede derivarse tacha alguna de ilegalidad dado que, según establece expresamente la LTAIPBG, "las obligaciones de transparencia contenidas en este capítulo se entienden si perjuicio de la aplicación de la normativa autonómica correspondiente o de otras disposiciones específicas que prevean un régimen más amplio en materia de publicidad" (art. 5.2 LTAIPBG). De este modo, la nueva norma básica estatal no sólo impide sino que favorece la ampliación del concepto y las obligaciones de publicidad en ella previstos. Y lo hace admitiendo que tal ampliación se realice tanto mediante la normativa autonómica como "de otras disposiciones específicas", previsión que proporciona plena cobertura a las ordenanzas municipales, siempre en el marco de la legislación básica estatal y, en su caso, de la normativa autonómica que la desarrolle.

\section{Limitaciones a la publicidad y criterios de ponderación}

Tan amplio concepto de información pública no resulta, sin embargo, ilimitado ${ }^{14}$. Existen límites, tanto en la modalidad de publicidad activa como en la de libre acceso a la información ${ }^{15}$. Algunos de ellos se derivan de la traslación al ámbito de la normativa de transparencia y libre acceso a la información de principios procedentes de la de protección de datos de carácter personal, principios que, desde luego, deberán observarse cuando resulte ésta aplicable, pero también cuando la normativa de transparencia invoca para sí la preferencia, siempre en el marco de la LOPD, ya que en ese ámbito hace suyos en gran medida tales principios. Es en este contexto en el que han de ubicarse las limitaciones a la publicidad derivadas de las reglas generales establecidas en la normativa de protección de datos personales sobre tratamiento de los mismos y, especialmente, dejando ahora al margen el régimen del consentimiento, al que me referiré posteriormente, las limitaciones resultantes de principios como los de calidad y proporcionalidad (art. 5.4 LTAIPBG). Desde la perspectiva de los regímenes de reutilización, publicidad y acceso, para lograr el imprescindible respeto al derecho a la protección de datos u otros intereses legítimos, resulta esencial la función que corresponde, primero, al principio de calidad y su hijuela, el de proporcionalidad; luego, al juicio de ponderación de los intereses en conflicto, el interés público preferente que impone la publicación frente al derecho a la protección de datos personales; y, por último, especialmente cuando el interés prevalente sea el segundo o lo imponga el principio de calidad, al proceso disociación de datos.

La OTLAI también incorpora expresamente estos principios haciéndolos suyos en relación a la materia que regula. Así, se refiere a los principios de publicidad de la información, estableciendo la presunción antes apuntada, impone al Ayuntamiento la obligación de impulsar la publicidad activa, garantiza la libre reutilización de cualquier información publicada o puesta a disposición por el Ayuntamiento "salvo causa justificada que lo impida", así como el carácter abierto de la información y su accesibilidad inmediata por medios electrónicos sin necesidad de previa solicitud garantizando en todo caso la aplicación, cuando proceda, de las limitaciones de acceso establecidas incorporando tales exigencias a los documentos electrónicos (art. 3.1 a 6, en conexión con el art. 8 OTLAI). Además, especialmente relevante en este sentido es la expresa incorporación a la OTLAI del principio de calidad de la información y, en conexión con el mismo, del compromiso de servicio (art. 3.7 y 8 OTLAI). La exigencia de calidad de la información impone que la que se facilite a la ciudadanía sea veraz, fehaciente y actualizada, indicándose la unidad responsable de la misma, la fecha de la última actualización y, siempre que los recursos lo permitan, que esté adaptada, dotándola de una estructura, presentación y redacción que facilite su completa comprensión por

así como los diarios y boletines oficiales del Ayuntamiento, había de publicarse en la sede electrónica con plenos efectos legales (arts. 24 y 25 $\mathrm{OAE}$ ). Resulta sorprendente que, en relación con estas cuestiones, no se estableciese en la OEA previsión alguna acerca de la protección de datos personales. Se echa en falta en ambas ordenanzas alguna previsión sobre los derechos de acceso, rectificación, cancelación y oposición regulados en la normativa de protección de datos, las consecuencias de la aplicación del principio de calidad a estos instrumentos, desarrollando lo previsto en el artículo 29 OTLAI, y las características de los motores de búsqueda que pudieran implementarse en la versión electrónica de los mismos, máxime cuando tales motores de búsqueda se contemplan como un elemento más de la sede electrónica en el artículo 28.2 OTLAI.

14 GUICHOT, 2011: 33-41, antes de la reciente normativa básica, lo puso de manifiesto con contundencia analizándolas y postulando su consideración como numerus clausus y su necesaria interpretación restrictiva.

15 MUÑOZ y BERMEJO, 2014: 229-237, de forma sugerente, identifican la información pública susceptible de ocultación por su ajenidad, cuando lo sea respecto de una entidad sometida a la normativa de transparencia; por su inmadurez, cuando no pueda considerarse conclusa en función de circunstancias diversas; por su carácter sensible, al generar perjuicios para determinadas materias; o por su indiscreción, en conexión con la normativa de protección de datos. 
el conjunto de la ciudadanía. En estrecha conexión con estas exigencias se impone, como compromiso de servicio, la exigencia de que la provisión de la información pública sea eficaz, rápida y de calidad.

Para interpretar adecuadamente el alcance del principio de calidad resulta de gran utilidad tomar como referencia su significado en la LOPD y el RPD. Conforme al principio de calidad, cuyo contenido y amplio alcance han sido exhaustivamente analizados desde la perspectiva de la protección de datos personales, la recogida y tratamiento de datos de carácter personal está sujeta a cuatro tipos de condicionantes. En primer lugar, han de considerarse los condicionantes relativos a la recogida, en cuya virtud los datos de carácter personal sólo se podrán recoger para su tratamiento, así como someterlos a dicho tratamiento, cuando sean adecuados, pertinentes y no excesivos en relación con el ámbito y las finalidades determinadas, explícitas y legítimas para las que se hayan obtenido (arts. 4.1 LOPD y 8.4 RPD), de manera que habrán de ser proporcionados al fin perseguido (al respecto, por todos, informe de la Agencia Española de Protección de Datos 145/2010), y deberán ser tratados de forma leal y lícita sin que puedan recogerse por medios fraudulentos, desleales o ilícitos (arts. 4.7 LOPD y 8.1 RPD). En segundo lugar, habrán de observarse los condicionantes relativos al uso y destino de los datos, que impiden utilizarlos para fines incompatibles con los que hubiesen justificado su recogida sin que se puedan considerarse incompatibles los fines históricos, estadísticos o científicos (arts. 4.2 LOPD y 8.2 y 3 RPD). En tercer lugar, habrán de atenderse también los condicionantes relativos al contenido y actualización, de modo que los datos han de ser precisos, exactos y estar actualizados para que respondan con veracidad a la situación actual del afectado (arts. 4.3 LOPD y 8.5 RPD), lo que se presumirá cuando sea él mismo quien los facilite. Si los datos de carácter personal registrados resultaran ser inexactos, en todo o en parte, o incompletos, serán cancelados y sustituidos de oficio por los correspondientes datos rectificados o completados, sin perjuicio de los derechos de rectificación y cancelación del titular, comunicándose a los posibles cesionarios, en caso de que existan. Por último, en cuarto lugar, deberán cumplirse los condicionantes relativos al mantenimiento de los datos, que deberán ser cancelados cuando hayan dejado de ser necesarios o pertinentes para la finalidad para la cual hubieran sido recabados o registrados (art. 4.5 LOPD y 8.6 RPD), si bien podrán conservarse durante el tiempo en que pueda exigirse algún tipo de responsabilidad derivada de una relación u obligación jurídica o de la ejecución de un contrato o de la aplicación de medidas precontractuales solicitadas por el interesado o atendiendo a valores históricos, estadísticos o científicos de acuerdo con su legislación específica. Consecuentemente, los datos no podrán conservarse de forma que permita la identificación del interesado durante un período superior al necesario para los fines en base a los cuales hubieran sido recabados o registrados ni, posteriormente, sin someterse a procedimientos de disociación (al respecto informe de la Agencia Española de Protección de Datos 408/2010).

Pero junto a tales limitaciones existen también otras de índole material establecidas en el artículo 14 LTAIPBG (que reproduce el art. $9 \mathrm{OTLAI})^{16}$. No se trata de ámbitos materiales exentos total y automáticamente del concepto de información pública. En ellos el órgano competente podrá restringir el acceso cuando exista un perjuicio para la seguridad nacional, la defensa, las relaciones exteriores, la seguridad pública, la prevención, investigación y sanción de los ilícitos penales, administrativos o disciplinarios, la igualdad de las partes en los procesos judiciales y la tutela judicial efectiva, las funciones administrativas de vigilancia, inspección y control, los intereses económicos y comerciales, la política económica y monetaria, el secreto profesional y la propiedad intelectual e industrial, la garantía de la confidencialidad o el secreto requerido en procesos de toma de decisión o la protección del medio ambiente. Siendo la LTAIPBG norma básica en su mayor parte, y en este punto en particular, no cabe admitir que las normas que la desarrollen amplíen los ámbitos materiales en los que pudiera restringirse la publicación, el acceso o la reutilización de la información dado que la excepción a norma básica ha de considerarse igualmente básica.

Mención específica requiere la regulación de los criterios para la concreta aplicación de las limitaciones a la publicidad, coincidentes en la ordenanza de Zaragoza y la ley básica estatal. Si la primera exige que se interpreten restrictivamente, que se justifique su aplicación (reiterando reglas generales de la Ley 30/1992), que se aplique de manera proporcionada a su objeto y a la finalidad de protección perseguida, ponderando el perjuicio causado al interés público con la denegación del acceso y el derecho a la protección de datos y restantes intereses legítimos protegidos por la limitación (art. 11 OTLAI), la segunda impone también la exigencia de motivación y proporcionalidad, así como atender a las circunstancias del caso, especialmente a la concurrencia de un interés público o privado superior que justifique el acceso (arts. 14 y 16 LTAIPBG). Siendo razonable tal interpretación restrictiva de

16 La OtTAIR, de nuevo, remite a la LTAIPBG añadiendo como criterio adicional que permite limitar la información pública el del ejercicio delegado de otras competencias estatales y autonómicas, según prevea la norma de delegación o, en su caso, respecto a cualquier información que la entidad local posea y que pudiera afectar a competencias propias o exclusivas de otra administración, cuyo derecho de acceso esté igualmente limitado por las leyes (art. 10 OtTAIR). Además, impone la ordenanza tipo que "en todo caso, la información se elaborará y presentará de tal forma que los límites referidos no sean obstáculo para su publicación o acceso” (art. 10 in fine), previsión que pudiera replicar en este ámbito lo que la disociación de datos personales comporta respecto de la aplicación de la normativa protectora que los regula. 
las limitaciones para evitar que sobre la base de las mismas pudiera reducirse en extremo la transparencia, ha de buscarse un adecuado equilibrio al respecto, determinante de la necesidad de ponderación, para prevenir la situación contraria, es decir, el sacrificio extremo del derecho a la protección de datos en el ara de una transparencia mal entendida.

\section{UN NUEVO MARCO DE RELACIÓN PARA LA PROTECCIÓN DE DATOS PERSONALES Y LA TRANSPARENCIA}

\section{Contenido y régimen jurídico básico}

La preocupación de la normativa sobre administración electrónica y transparencia, acceso a la información pública y reutilización resulta plenamente coherente con la importancia y desarrollo que ha alcanzado en nuestros días la protección de datos de carácter personal, configurada en nuestro ordenamiento como una de las manifestaciones del derecho fundamental a la intimidad personal (FERNÁNDEZ SALMERÓN, 2003: 69-83; BLANES, 2014: 316), según acabamos de precisar, estrechamente vinculado al derecho a la intimidad personal y encuadrado, especialmente en la medida en que se implanta y desarrolla la administración electrónica, en el expreso mandato constitucional conforme al cual "la ley limitará el uso de la informática para garantizar el honor y la intimidad personal y familiar de los ciudadanos y el pleno ejercicio de sus derechos” (art. 18.4 Constitución) ${ }^{17}$. Fácilmente se comprende que, como ha reclamado la doctrina, resulte en extremo necesaria una regulación coherente y equilibrada de transparencia y protección de datos ${ }^{18}$.

Aun cuando no aparezca de manera literal entre los derechos y libertades recogidos en la sección primera del capítulo segundo del título I de la Constitución, el derecho a la protección de datos se enmarca en lo establecido en los apartados primero y cuarto del artículo 18 de la misma, que establecen respectivamente que "se garantiza el derecho al honor, a la intimidad personal y familiar y a la propia imagen" y que "la ley limitará el uso de la informática para garantizar el honor y la intimidad personal y familiar de los ciudadanos y el pleno ejercicio de sus derechos", en conexión con diversos acuerdos internacionales suscritos por España y de conformidad con el artículo 10.2 de la propia Constitución. Según se afirmó en la Sentencia del Tribunal Constitucional 142/1993, de 22 de abril, "el atributo más importante de la intimidad. como núcleo central de la personalidad, es la facultad de exclusión de los demás, de abstención de injerencias por parte de otro, tanto en lo que se refiere a la toma de conocimientos intrusiva como a la divulgación ilegítima de esos datos. La conexión de la intimidad con la libertad y dignidad de la persona implica que la esfera de la inviolabilidad de la persona frente a injerencias externas, el ámbito personal y familiar, sólo en ocasiones tenga proyección hacia el exterior, por lo que no comprende en principio los hechos referidos a las relaciones sociales y profesionales en que se desarrolla la actividad laboral, que están más allá del ámbito del espacio de intimidad personal y familiar sustraído a intromisiones extrañas por formar parte del ámbito de la vida privada (STC 170/1987)" (STC 142/1993, FJ. 7).

Por otra parte, el artículo 18.4 "contiene un instituto de garantía de los derechos a la intimidad y al honor y del pleno disfrute de los restantes derechos de los ciudadanos que es, además, en sí mismo, «un derecho fundamental, el derecho a la libertad frente a las potenciales agresiones a la dignidad y a la libertad de la persona provenientes de un uso ilegítimo del tratamiento automatizado de datos, lo que la Constitución llama 'la informática'» (STC 254/1993, de 20 de julio, F.J. 6, doctrina que se reitera en las SSTC 143/1994, de 9 de mayo, F.J. 7; 11/1998, de 13 de enero, F.J. 4; 94/1998, de 4 de mayo, F.J. 6, y 202/1999, de 8 de noviembre, F.J. 2)" (STC 290/2000, de 30 de noviembre, FJ. 7). Ha afirmado el Tribunal Constitucional, sintéticamente, que "el contenido del derecho fundamental a la protección de datos consiste en un poder de disposición y de control sobre los datos personales que faculta a la persona para decidir cuáles de esos datos proporcionar a un tercero, sea el Estado o un particular, o cuáles puede este tercero recabar, y que también permite al individuo saber quién posee esos datos personales y para qué, pudiendo oponerse a esa posesión o uso. Estos poderes de disposición y control sobre los datos personales, que constituyen parte del contenido del derecho fundamental a la protección de datos se concretan jurídicamente en la facultad de consentir la recogida, la obtención y el acceso a los datos personales, su posterior almacenamiento y tratamiento, así como su uso o usos posibles, por un tercero, sea el Estado o un particular. Y ese derecho a consentir el conocimiento y el tratamiento, informático o no, de los datos personales, requiere como complementos indispensables, por un lado, la facultad de saber en todo momento quién dispone de esos datos personales y a qué uso los está sometiendo, y, por otro lado, el poder oponerse a esa posesión y usos" (STC 292/2000, de 30 de noviembre, FJ. 7)

17 Sobre la configuración del derecho a la protección de datos en la jurisprudencia constitucional y el debate doctrinal acerca de su carácter autónomo, por el que se inclina el autor, o su vinculación a un derecho a la intimidad ampliado, por todos, GUICHOT, $2011: 306-218$.

18 BLANES, 2014: 315-316 e, in extenso, 315-326; FERNÁNDEZ y PÉREZ, 2014: 179-211. Ya antes GUICHOT, 2005: 343-349, criticando la nula regulación, y especialmente el propio GUICHOT, 2009: 171-224. MARTínEZ, 2014: 259, considera que "el derecho fundamental a la protección de datos se erige en el más que probable muro de contención para la transparencia de nuestras administraciones”. 
Atendiendo a lo que se acaba de exponer, se entiende perfectamente que la protección de datos personales ha sido el filtro fundamental, desde la perspectiva de los derechos individuales, por el que han tenido que pasar el proceso de implantación de la administración electrónica, la transparencia y la garantía de acceso a la información pública y su reutilización. Al tiempo que el avance tecnológico ha permitido el tratamiento y difusión masiva de la información, se han acentuado los riesgos para la protección de datos personales, si bien está siendo ese mismo avance tecnológico el que está proporcionando las respuestas y procedimientos técnicos para eliminar tales riesgos y continuar preservando el derecho a la protección de los datos personales en la forma constitucional y legalmente establecida.

La LOPD y RPD incorporaron a nuestro ordenamiento lo establecido en la Directiva 95/46/CE, del Parlamento Europeo y del Consejo, de 24 de octubre de 1995, relativa a la protección de las personas físicas en lo que respecta al tratamiento de datos personales y a la libre circulación de estos datos. La LOPD tiene por objeto garantizar y proteger, en lo que concierne al tratamiento de los datos personales, las libertades públicas y los derechos fundamentales de las personas físicas, y especialmente de su honor e intimidad personal y familiar (art. 1 LOPD). Se aplica a los datos de carácter personal registrados en soporte físico, que los haga susceptibles de tratamiento, y a toda modalidad de uso posterior de estos datos por los sectores público y privado, todo ello en los términos establecidos en el artículo 2 LOPD. Los conceptos de dato de carácter personal y fichero son sumamente amplios, alcanzando el primero a "cualquier información concerniente a personas físicas identificadas o identificables [art. 3.a) LOPD], viva", y el segundo a "todo conjunto organizado de datos de carácter personal, cualquier que fuere la forma o modalidad de su creación, almacenamiento, organización y acceso” [art. 3.b) LOPD].

Pero la normativa de protección de datos personales sólo desarrollará su fuerza protectora cuando estos no resulten disociados ${ }^{20}$. Resultan esenciales, por ello, los conceptos de tratamiento de datos y de disociación. Se entenderá por tratamientos de datos, cuestión especialmente relevante para este estudio, las "operaciones y procedimientos técnicos de carácter automatizado o no, que permitan la recogida, grabación, conservación, elaboración, modificación, bloqueo y cancelación, así como las cesiones de datos que resulten de comunicaciones, consultas, interconexiones y transferencias" [art. 3.c) LOPD]. Se considerará procedimiento de disociación "todo tratamiento de datos personales de modo que la información que se obtenga no pueda asociarse a persona identificada o identificable" [art. 3.f) LOPD]. Finalmente, se define como cesión o comunicación de datos “toda revelación de datos realizada a una persona distinta del interesado" [art. 3.i) LOPD].

Es sobre esta base, atendiendo muy especialmente al concepto de información pública al que me he referido anteriormente, sobre la que habrá de construirse la normativa de transparencia. El Proyecto de ley de transparencia preveía inicialmente que "cuando la solicitud de acceso se refiera a información pública que contenga datos de carácter personal se aplicarán las disposiciones previstas en esta Ley", si bien "se aplicará la normativa de protección de datos personales cuando los que contenga la información se refieran únicamente al solicitante, sin perjuicio de que, en este caso, el otorgamiento del acceso permita el conocimiento del solicitante no sólo de los datos que contenga la información de los que sea titular, sino de ésta en su totalidad" (art. 15.1 del Proyecto de LTAIPBG). Finalmente, tales previsiones desaparecieron de la LTAIPBG, cuyo artículo 15 incorpora los planteamientos del Consejo de Estado y la Agencia Española de Protección de Datos que, a la postre, determinan su inserción en el ordenamiento jurídico como Ley especial en el contexto de la LOPD, de modo que para el acceso a información que contenga datos propios de quien lo solicita se aplicará una u otra Ley a su elección. En los demás casos (acceso a datos ajenos o a propios y ajenos no disociables), se aplicará la LTAIPBG, que permite modular la exigencia de consentimiento, dado su rango formal de Ley, conforme a lo previsto en el inciso final del artículo 6.1 LOPD, genéricamente respecto al tratamiento, y 11.2.b) LOPD específicamente en cuanto a la cesión remitiendo genéricamente al juicio de ponderación en ella regulado (art. 15.3 LTAIPBG) (FERNÁNDEZ y PÉREZ, 2014: 186). Obviamente, queda al margen el caso en que el acceso tenga lugar previa disociación de los datos de carácter personal de modo que se impida la identificación de las personas afectadas, no cubierto por la eficacia protectora de la normativa reguladora de los datos de carácter personal (art. 15.4 LTAIPBG).

Cuestión distinta es que, como expondré más adelante, el régimen que incorpora el artículo 15 de la LTAIPBG hace suyas determinadas previsiones acerca del consentimiento para el tratamiento de datos especialmente

19 El artículo 11.2, primer párrafo, OtTAIR prevé en este sentido que "la protección de los datos de carácter personal no supondrán un límite para la publicidad activa y el acceso a la información pública cuando el titular del dato haya fallecido, salvo que concurran otros derechos".

20 El artículo 11.2, segundo párrafo, OtTAIR propone establecer que "no se aplicará este límite cuando los titulares de los datos los hubieran hecho manifiestamente públicos previamente o fuera posible la disociación de los datos de carácter personal sin que resulte información engañosa o distorsionada y sin que sea posible la identificación de las personas afectadas". 
protegidos, entre otros, quebrando en tales supuestos la regla general que establece y que remite a una "ponderación suficientemente razonada del interés público en la divulgación de la información y los derechos de los afectados cuyos datos aparezcan en la información solicitada, en particular su derecho fundamental a la protección de datos de carácter personal" (art. 15.3 LTAIPBG). Y ello, en todo caso, y al igual que ocurre conforme al artículo 11.6 LOPD, siempre que no se hayan disociado los datos personales, pues "no será aplicable lo establecido en los apartados anteriores si el acceso se efectúa previa disociación de los datos de carácter personal de modo que se impida la identificación de las personas afectadas" (art. 15.4 LTAIPBG).

Aprobada la LTAIPBG el expuesto sería el régimen aplicable para la protección de datos personales, dado que, como ha quedado dicho, aparece configurada en su mayor parte como norma básica (disposición final octava LTAIPBG) y, en lo que respecta a la regulación de la publicidad activa, de mínimos. Queda así superado el escenario anterior conformado por la LAP, LOPD y sus disposiciones de desarrollo, un marco notablemente más restrictivo ( $y$ transitoriamente vigente, conforme a la propia LTAIPBG). Y es que, al no contar con una ley especial habilitante, rol que ahora asume la LTAIPBG, se aplicaba la exigencia general de consentimiento para el tratamiento establecida en la normativa de protección de datos, con las amplias excepciones igualmente previstas en la misma con carácter general (arts. 6 a 8 LOPD) ${ }^{21}$. No obstante, en tal contexto y configurada inequívocamente la publicación como cesión conforme a la normativa de protección de datos, aun cuando no exista un cesionario determinado, la posibilidad de tratamiento y cesión en ausencia de consentimiento había de valorarse en función de lo establecido en el artículo 6.2 in fine LOPD, que establece que no será preciso el consentimiento, entre otros casos, "cuando los datos figuren en fuentes accesibles al público y su tratamiento sea necesario para la satisfacción del interés legítimo perseguido por el responsable del fichero o por el del tercero a quien se comuniquen los datos, siempre que no se vulneren los derechos y libertades fundamentales del interesado", precepto que ha de interpretarse conforme a la Directiva, según expondré a continuación. Sobre tal base, específicamente en relación con la cesión el artículo 11.1 LOPD ratifica la exigencia de consentimiento previo, pero prevé una serie de excepciones, entre las que destaca la expresa previsión en una Ley, además de otros supuestos establecidos en el artículo 11.2 LOPD. En cualquier caso, va de suyo que de someterse la información al proceso de disociación, escapando de este modo del ámbito de aplicación de la LOPD, ningún obstáculo existía en el contexto normativo anterior, ni por supuesto en el actual, a su publicación o puesta a disposición.

Así pues, aunque pudiera parecer que antes de la LTAIPBG y en ausencia de tratamiento de disociación no cabía cesión, ni en consecuencia publicidad activa, ni tan siquiera previa ponderación del interés público que lo justificase garantizando la preservación del derecho a la protección de datos no ocurría así. De lo contrario tal marco normativo hubiera constituido un obstáculo difícilmente salvable para hipotéticas ordenanzas municipales o políticas locales de transparencia. Pero no lo era. La Sentencia del Tribunal de Justicia de la Unión Europea de 24 de noviembre de 2011 declaró el efecto directo del artículo 7.f) de la Directiva 95/46/CE, del Parlamento Europeo y del Consejo, de 24 de octubre de 1995, relativa a la protección de las personas físicas en lo que respecta al tratamiento de datos personales y a la libre circulación de estos datos, y condujo a una conclusión contraria que proporcionaba cobertura suficiente en la LOPD a la normativa local sobre transparencia aun antes de la aprobación de la LTAIPBG. El Tribunal de Justicia declaró que el citado precepto de la Directiva "se opone a una normativa nacional que, para permitir el tratamiento de datos personales necesario para la satisfacción de interés legítimo perseguido por el responsable del tratamiento o por el tercero o terceros a los que se comuniquen los datos, exige, en el caso de que no exista consentimiento del interesado, no sólo que se respeten los derechos y libertades fundamentales de éste, sino además que dichos datos figuren en fuentes accesibles al público, excluyendo así de forma categórica y generalizada todo tratamiento de datos que no figuren en tales fuentes" (apartado primero del fallo).

Abordaré a continuación la exigencia de consentimiento en la normativa de protección de datos, entre otras garantías derivadas del derecho a su protección, para continuar posteriormente con la regulación de los aspectos atinentes a la protección de datos personales en la LTAIPBG, marco actual, junto a algunas leyes autonómicas que incluyen su ámbito subjetivo de aplicación a la administración local, de las ordenanzas municipales de transparencia.

\section{La información previa y la necesidad de consentimiento del titular de los datos para el tratamiento y otras garantías legales}

El conjunto de facultades que el derecho fundamental a la protección de datos de carácter personal otorga a su titular se concreta, entre otras cuestiones, en exigencias de información previa al tratamiento (art. 5.1 LOPD),

21 Precisamente la necesidad de contar con una ley especial que eximiese del consentimiento la cesión era una de las cinco razones fundamentales que exigían la aprobación de una ley de transparencia a juicio de PIÑAR, 2011: 243-244 o, in extenso, ya antes, PIÑAR, 2009. La exigencia del artículo 105.b) de la Constitución, la insuficiencia del artículo 37 de la Ley 30/1992, el avance tecnológico que permite recopilar y tratar ingentes cantidades de datos y la vinculación de transparencia y democracia fueron las otras cuatro razones esgrimidas por este autor. 
primero, la exigencia de su consentimiento para el tratamiento de los datos, en segundo lugar (art. 6.1 LOPD) y la ratificación de la necesidad de consentimiento para la comunicación de los datos, finalmente (art. 11 LOPD). Se conforma sobre estas bases un régimen riguroso que subordina el tratamiento al consentimiento del titular de los datos personales y que, lógicamente, puede entrar en colisión con la amplia concepción de la transparencia derivada de su normativa reguladora ${ }^{22}$.

Desde la primera perspectiva, los interesados a los que se soliciten datos personales deberán ser previamente informados de modo expreso, preciso e inequívoco, como regla general, de la existencia de un fichero o tratamiento de datos de carácter personal, de la finalidad de la recogida de éstos y de los destinatarios de la información; del carácter obligatorio o facultativo de su respuesta a las preguntas que les sean planteadas; de las consecuencias de la obtención de los datos o de la negativa a suministrarlos; de la posibilidad de ejercitar los derechos de acceso, rectificación, cancelación y oposición y de la identidad y dirección del responsable del tratamiento o, en su caso, de su representante (art. 5.1 LOPD).

Sobre la base de lo anterior, el consentimiento inequívoco del titular de los datos es la regla general que condiciona su tratamiento, "salvo que la ley disponga otra cosa" (art. 6.1 LOPD), previsión amparada en el artículo 8, especialmente apartado cuarto, de la Directiva. Además, asumiendo directamente la habilitación realizada a favor de otras leyes, la propia LOPD prevé amplias excepciones al principio de consentimiento previo al tratamiento y establece, a este respecto, que "no será preciso el consentimiento cuando los datos de carácter personal se recojan para el ejercicio de las funciones propias de las Administraciones públicas en el ámbito de sus competencias; cuando se refieran a las partes de un contrato o precontrato de una relación negocial, laboral o administrativa y sean necesarios para su mantenimiento o cumplimiento; cuando el tratamiento de los datos tenga por finalidad proteger un interés vital del interesado en los términos del artículo 7, apartado 6, de la presente Ley, o cuando los datos figuren en fuentes accesibles al público y su tratamiento sea necesario para la satisfacción del interés legítimo perseguido por el responsable del fichero o por el del tercero a quien se comuniquen los datos, siempre que no se vulneren los derechos y libertades fundamentales del interesado" (art. 6.2 LOPD).

El artículo 6.2 LOPD ha de ser interpretado, tal cual ha quedado señalado anteriormente, de conformidad con el artículo 7.f) de la citada Directiva 95/46/CE, cuyo efecto directo declaró la Sentencia del Tribunal de Justicia de la Unión Europea de 24 de noviembre de 2011 rechazando que la excepción al consentimiento basada en la necesidad del tratamiento para la satisfacción del interés legítimo perseguido por el responsable del fichero o por el del tercero a quien se comuniquen los datos, siempre que no se vulneren los derechos y libertades fundamentales del interesado, pueda condicionarse a la inclusión de dichos datos en fuentes accesibles al público. El Tribunal de Justicia, además, hace especial hincapié en la necesidad de ponderación de los intereses, derechos y libertades en presencia admitiendo que los legisladores nacionales fijen criterios para la realización de esa ponderación, que reduzcan la discrecionalidad del órgano competente, criterios que no pueden llegar a excluir o predeterminar la ponderación misma, como ocurriría conforme a una interpretación literal de la norma española que impediría el tratamiento de datos no incluidos en fuentes accesibles al público sin consentimiento. A este respecto, por lo demás, resulta de especial interés el Informe de la Agencia Española de Protección de Datos de 5 de junio de 2012, en relación con la LTAIPBG, especialmente en sus apartados X a XV, a los que me referiré más adelante.

Ha de tenerse presente que, aun en los casos en los que no sea necesario el consentimiento del afectado para el tratamiento de los datos de carácter personal, y siempre que una ley no disponga lo contrario, éste podrá oponerse a su tratamiento cuando existan motivos fundados y legítimos relativos a una concreta situación personal. En tal supuesto, el responsable del fichero excluirá del tratamiento los datos relativos al afectado (art. 6.4 LOPD). En todo caso, cuando el interesado haya prestado su consentimiento al tratamiento, podrá revocarlo cuando exista causa justificada para ello y no se le atribuyan efectos retroactivos (art. 6.3 LOPD). Reglamentariamente se prevé que el afectado podrá revocar su consentimiento a través de un medio sencillo, gratuito y que no implique ingreso alguno para el responsable del fichero o tratamiento (art. 17 RPD).

El concepto de "fuentes accesibles al público" se concreta, limitativamente, por referencia a "aquellos ficheros cuya consulta puede ser realizada, por cualquier persona, no impedida por una norma limitativa o sin más exigencia que, en su caso, el abono de una contraprestación. Tienen la consideración de fuentes de acceso públi-

22 Eso explica que normas anteriores a la LTAIPBG como la Ley Foral Navarra 11/2012, de 21 de junio, de la Transparencia y del Gobierno Abierto, resulten notablemente restrictivas al incluir un amplio catálogo de limitaciones del derecho de acceso a la información pública entre las que se recoge, con términos categóricos que luego parece modular la propia norma, "la protección de los datos de carácter personal, siempre que la persona interesada a quien conciernan no haya consentido su tratamiento o revelación. En todo caso, se estará a lo dispuesto en la Ley Orgánica de Protección de Datos de Carácter Personal” [artículos 23.1.b) y, modulando el alcance limitativo del consentimiento, 24]. Más equilibrada resulta, entre las normas legales anteriores a la LTAIPBG, la Ley 4/2013, de 21 de mayo, de Gobierno Abierto de Extremadura (artículo 17). 
co, exclusivamente, el censo promocional, los repertorios telefónicos en los términos previstos por su normativa específica, las listas de personas pertenecientes a grupos de profesionales que contengan únicamente los datos de nombre, título, profesión, actividad, grado académico, dirección e indicación de su pertenencia al grupo. Asimismo, tienen el carácter de fuentes de acceso público los diarios y boletines oficiales y los medios de comunicación" [art. 3.j) LOPD]. El concepto de "fuentes accesibles al público" es de carácter tasado, de modo que no caben normas legales u ordenanzas que lo amplíen²3.

La exigencia de consentimiento resulta especialmente intensa en relación con los que la LOPD define como datos especialmente protegidos, es decir los "datos personales que revelen la ideología, afiliación sindical, religión y creencias" (art. 7.2 LOPD), el "origen racial, a la salud y a la vida sexual” (art. 7.3 LOPD). En relación con estos datos se requiere consentimiento expreso y por escrito, si bien se exceptúan los ficheros mantenidos por los partidos políticos, sindicatos, iglesias, confesiones o comunidades religiosas y asociaciones, fundaciones y otras entidades sin ánimo de lucro, cuya finalidad sea política, filosófica, religiosa o sindical, en cuanto a los datos relativos a sus asociados o miembros, sin perjuicio de que la cesión de dichos datos precisará siempre el previo consentimiento del afectado (art. 7.3 LOPD). La normativa de transparencia, como explicaré, resulta especialmente tuitiva con el titular de los datos en estos casos exigiendo su consentimiento o que el acceso a la información esté amparado por norma legal, de modo que en este ámbito el margen del que disponen las ordenanzas municipales de transparencia resulta estrecho, limitado al que otorga la normativa básica estatal y, en su caso y no sin dificultades competenciales, la normativa autonómica que incluye a la administración local en su ámbito subjetivo de aplicación.

Aun cuando no se trate sino de una especie más del genérico tratamiento de los datos personales [conforme al art. 3.c) LOPD], la normativa de protección de datos regula específicamente la necesidad de consentimiento para la comunicación de datos (art. 11 LOPD). Tal exigencia ha de ser interpretada, de nuevo, conforme a la Sentencia del Tribunal de Justicia de la Unión Europea de 24 de noviembre de 2011. En principio, "los datos de carácter personal objeto del tratamiento sólo podrán ser comunicados a un tercero para el cumplimiento de fines directamente relacionados con las funciones legítimas del cedente y del cesionario con el previo consentimiento del interesado" (art. 11.1 LOPD). Pero el consentimiento no será preciso, entre otros supuestos, "cuando la cesión esté autorizada en una Ley" [art. 11.2.b) LOPD], de modo que, atendiendo al efecto directo del artículo 7.f) de la Directiva 95/46/CE en la interpretación que realizó la citada Sentencia de 24 de noviembre de 2011, ha de entenderse que la excepción al consentimiento genérico del tratamiento cuando sea necesario para la satisfacción del interés legítimo perseguido por el responsable del fichero o por el del tercero a quien se comuniquen los datos, siempre que no se vulneren los derechos y libertades fundamentales del interesado (art. 6.2 LOPD) proporcionará cobertura también a la comunicación. La cuestión resulta decisiva desde la perspectiva de la transparencia, especialmente hasta la aprobación de la LTAIPBG que, como ha quedado señalado, tendría carácter de ley autorizante a los efectos y en el marco de la LOPD.

Al margen de las esenciales garantías de información y consentimiento para el tratamiento que se acaban de examinar, la LOPD establece también la exigencia de medidas de seguridad, de índole fundamental pero no exclusivamente técnica (art. 9 LOPD y 79 a 114 RPD). Las medidas de seguridad, que corresponde adoptar al responsable del fichero y, en su caso, al encargado del tratamiento, son de naturaleza técnica y organizativa y tienen por objeto garantizar la seguridad de los datos de carácter personal y evitar su alteración, pérdida, tratamiento o acceso no autorizado, habida cuenta del estado de la tecnología, la naturaleza de los datos almacenados y los riesgos a que están expuestos, ya provengan de la acción humana o del medio físico o natural (art. 9.1 LOPD). De no cumplirse las condiciones resultantes de las medidas de seguridad está prohibido registrar los datos en los correspondientes ficheros o utilizar para ello los centros de tratamiento, locales, equipos, sistemas y programas, al considerar la norma que no está garantizada su integridad y seguridad (art. 9.2 LOPD). La LOPD realizó una

23 La OTLAI, en la versión inicialmente aprobada, establecía a este respecto que se entenderían procedentes de las fuentes accesibles al público "toda la información referente a los cargos y empleados del Ayuntamiento que esté directamente relacionada con la organización, el funcionamiento o las actividades del mismo, incluyéndose en la misma el nombre, cargo o función, órgano de pertenencia o unidad administrativa de destino, títulos académicos exigidos para el ejercicio de sus función, forma de acceso al puesto y dirección profesional”, así como "la agenda de los cargos electos municipales" (art. 10 OTLAI). En la versión finalmente aprobada, en cambio, incluye tal información, junto a otras, entre aquellas en las que se presume la existencia de interés público preferente a los efectos de su divulgación y en relación con el juicio de ponderación preciso. Nada cabía objetar a la previsión inicial, que no era posible interpretar como una ampliación de las “fuentes accesibles al público" sino como mera declaración del carácter público de la información a la que se refería, ni desde la perspectiva de la normativa de protección de datos, aunque resultase precisa o conveniente en ocasiones su disociación, ni desde la de la normativa de empleo público. Menos aún puede objetarse la regulación finalmente adoptada. Ahora bien, la relación de servicio o de empleo con una administración no legitima la difusión de cualesquiera datos personales asociados a los empleados públicos, tal y como se desprende, por ejemplo, de la Resolución AP/00007/2010, de 12 de abril, Agencia Española de Protección de Datos, en relación con datos tales como las horas trabajadas, el sueldo íntegro mensual y el total de pagas extras anuales (a lo que se atiene estrictamente el art. 20.1 OTLAI). 
amplia remisión normativa que permitió al RPD establecer tres niveles de seguridad diferenciados para ficheros y tratamientos automatizados y no automatizados que deberán desarrollarse en cada caso en los correspondientes documentos de seguridad.

\section{Los datos personales y la administración electrónica. Metadatos complementarios sobre datos personales. Implicaciones para la ponderación y disociación}

Siendo preceptiva la información al titular de los datos y resultando exigible, como regla general, su consentimiento para el tratamiento, resulta decisiva para una adecuada implantación de la normativa de transparencia y acceso a información pública la implementación tecnológica y jurídica de tales exigencias. Lo mismo cabe afirmar atendiendo a las relevantes consecuencias del principio de calidad de los datos establecido en la normativa de protección de datos personales (art. 4 LOPD) ${ }^{24}$. La transición hacia la administración electrónica debiera garantizar que quede constancia de la existencia de datos personales en los diferentes procedimientos o clases de documentos y las medidas de seguridad aplicables a los mismos, reflejándose el tratamiento de datos personales en los metadatos de cada documento electrónico, indicando si proceden las medidas de seguridad aplicables a los mismos conforme a la LOPD y al RPD ${ }^{25}$. El problema surge cuando no exista indicación acerca de la posibilidad de tratamiento, pues frente a la prudencia que induce a considerar razonable prever por defecto que no sea posible el acceso a tales datos ${ }^{26}$, se imponen las presunciones legales y reglamentarias del carácter público de la información ${ }^{27}$.

Una adecuada integración de transparencia y administración electrónica exige, a mi juicio, que los documentos electrónicos indiquen expresamente si incorporan datos personales, fijando las posibles limitaciones conforme a los criterios de la normativa de protección de datos y de transparencia y, en su caso, su régimen derivado de las medidas de seguridad de que se beneficien. De no ser así, surge el problema evidente de si otorgar primacía a la protección de datos personales, exigiendo que el documento electrónico quede configurado de modo que se impida accesos indebidos a los mismos, o a la transparencia, imponiendo la configuración contraria por defecto. Las implicaciones de la primera alternativa, que es la adoptada en Zaragoza, según he expuesto, resultan tan obvias como su colisión con las exigencias del principio de transparencia como luego se verá al analizar las consecuencias del principio de calidad o la obligación de disociación de datos ${ }^{28}$.

Por lo demás, la gestión de la información pública es objeto de especial atención cuando a la información recogida en documentos electrónicos se refiere. Así, aun cuando sea en relación con el portal de transparencia, base de la publicidad activa, la normativa básica, remitiendo las prescripciones técnicas a desarrollo reglamentario,

24 Al respecto, artículos 3.1.a) y b) y 7.6 OtTAIR y 3.6 y 7 OTLAI. Conforme al artículo 7.6 OtTAIR "la información pública que se facilite a las personas debe ser veraz, fehaciente y actualizada. En toda publicación y puesta a disposición se indicará la unidad responsable de la información y la fecha de la última actualización. Asimismo, los responsables de la publicación adaptarán la información a publicar, dotándola de una estructura, presentación y redacción que facilite su completa comprensión por cualquier persona".

25 A este respecto, en Zaragoza, artículo 8.1 OAE, que trae causa, entre otros, del art. 31 LAESP. En Zaragoza, cada dato o documento integrante de la información pública contará con información sobre las limitaciones a la publicidad, estableciendo a tal efecto que "los documentos y conjuntos de datos deberán incorporar información sobre la aplicabilidad a los mismos de las limitaciones a la publicidad, de forma que sea posible permitir o denegar automáticamente el acceso a su contenido. Las plantillas de los documentos tendrán definidos valores por defecto para esta información y los empleados municipales cuidarán de que esté siempre cumplimentada con los valores apropiados" [art. 7.1.h) OTLAI]. Además, al regular las clases de documentos, entre los metadatos exigibles se incluye el indicativo de "la posibilidad de libre consulta una vez terminado el procedimiento al que se refiere o, en caso contrario, las causas aplicables para restringir el acceso" [art. 51.3.a) $\mathrm{OAE}$. De hecho, entre los principios generales, se incluye el denominado principio de "privacidad en el diseño", conforme al cual "el diseño, desarrollo y gestión de los sistemas de información municipales se realizarán de forma que se garantice la correcta aplicación de las limitaciones al acceso previstas en esta Ordenanza. Al objeto de permitir el acceso automatizado y por medios electrónicos a la información se incluirá en los conjuntos de datos y en los documentos información precisa sobre la aplicabilidad de dichas limitaciones" (art. 3.6 OTLAI). Toda la información pública, por tanto, a través de metadatos de documentos, conjuntos de documentos o conjuntos de datos, deberá indicar la existencia de limitaciones conforme a lo establecido en los artículos 9 y 10, éste último dedicado a la protección de datos personales, de la propia OTLAI.

26 Para estos casos establece el artículo 8 OEA que "el valor asignado por defecto deberá ser tal que impida los accesos indebidos a información de carácter personal”.

27 Recuérdese la presunción establecida por el artículo 13 LTAIPBG conforme al cual "se entiende por información pública los contenidos o documentos, cualquiera que sea su formato o soporte, que obren en poder de alguno de los sujetos incluidos en el ámbito de este título y que hayan sido elaborados o adquiridos en el ejercicio de sus funciones". Si el artículo 8 OtTAIR, el artículo 6.1 OTLAI reproduce casi literalmente la presunción precisando, además, que "podrá estar en soporte papel o en formato electrónico y, en este segundo caso, tener la forma de datos o de documentos electrónicos”. Con diversos matices la presunción existe también en la legislación andaluza y, con menor intensidad, en la legislación riojana, extremeña o navarra, aun siendo anteriores las dos últimas a la normativa básica estatal. No ocurre lo mismo, en cambio, en la normativa gallega, muy anterior a la LTAIPBG, que por ello limita el derecho a obtener información a aquella que afecte a sus derechos e intereses legítimos.

28 De hecho, la propia normativa municipal zaragozana lo advierte al establecer que "sin embargo, el Ayuntamiento deberá obrar para evitar que la aplicación de este principio deje sin efecto los derechos de consulta y de acceso a la información administrativa por parte de la ciudadanía previstos en esta Ordenanza" (art. 8.2 in fine OEA). 
impone los principios de accesibilidad, de modo que se proporcione información estructurada sobre los documentos y recursos de información con vistas a facilitar la identificación y búsqueda de información; interoperabilidad, exigiendo el cumplimiento del esquema nacional de interoperabilidad aprobado mediante Real Decreto 4/2010, de 8 de enero, y de las normas técnicas de interoperabilidad; y reutilización, con las consecuencias correspondientes sobre los formatos y en los términos previstos en la Ley 37/2007, de 16 de noviembre, sobre reutilización de la información del sector público29.

Ya antes, el artículo 42.4 del Real Decreto 1671/2009, de 6 de noviembre, por el que se desarrolla parcialmente la Ley 11/2007, de 22 de junio, de acceso electrónico de los ciudadanos a los servicios públicos (en lo sucesivo RAESP), remitió también al esquema nacional de interoperabilidad la determinación de los metadatos mínimos obligatorios asociados a los documentos electrónicos. El anexo I al que remite el apartado V.1 de la Resolución de 19 de julio de 2011, de la Secretaría de Estado para la Función Pública, por la que se aprueba la Norma Técnica de Interoperabilidad de Documento Electrónico, en el marco de lo previsto en la disposición adicional primera del Real Decreto 4/2010, de 8 de enero, por el que se regula el Esquema Nacional de Interoperabilidad en el ámbito de la Administración Electrónica, no incluyó entre los metadatos mínimos obligatorios los relativos a la existencia de datos personales o a las medidas de protección que pudieran resultar de aplicación, pero el apartado V.2 prevé que "se podrán asignar metadatos complementarios para atender a necesidades de descripción específicas". Nada obsta, en consecuencia, para la inclusión de metadatos complementarios sobre tales cuestiones en función de lo que establezcan las ordenanzas municipales.

Antes de la LTAIPBG, la regulación del derecho de acceso en la OEA se basó precisamente en la indicación, mediante los correspondientes metadatos, de la posibilidad de acceso a los documentos de que se tratase, así como de la circunstancia de que hubiese concluido o no el procedimiento correspondiente. Ello resultaba plenamente coherente tanto con el sucintamente expuesto régimen de protección de datos como con la regulación del derecho de acceso en el artículo 37 LAP previo a la LTAIPBG. Los interesados, y no otras personas, de acuerdo con dicho precepto y el artículo 35.a) LAP, podrán acceder automáticamente a documentos electrónicos correspondientes a expedientes no terminados cuando así se indique en sus metadatos quedando obligados, en otro caso, a formular solicitud (art. 60.3 OAE). Tratándose de documentos electrónicos relativos a procedimientos ya terminados, siempre que no se vieran afectados por las limitaciones establecidas en el artículo 37 LAP, podían ser objeto de libre acceso por la ciudadanía y, si así se indica en los metadatos, de modo inmediato (art. 60.4 OEA). Actualmente, como expondré más adelante al analizar el trámite de inadmisión, tales precisiones pudieran continuar siendo válidas, a mi juicio, al mantenerse la restricción del artículo 35.a) LAP. La cuestión pudiera haberse resuelto en LTAIPBG con mayor claridad y contundencia, atendiendo a los criterios jurisprudenciales sobre acceso a la información ambiental, si bien resulta previsible que se mantenga el actual debate doctrinal acerca del acceso a información obrante en procedimientos en curso $^{30}$, al menos hasta que quede sentada doctrina legal al respecto ${ }^{31}$.

29 La OtTAIR exige, en este sentido, que "la gestión de la información, y especialmente de aquella que se encuentre en formato electrónico, se hará de forma que cada dato o documento sea único, compartido, accesible, estructurado, descrito con información sobre las limitaciones de uso y, en su caso, ubicado geográficamente" [art. 9.a) OtTAIR]. La OTLAl establece también reglas relativas a los datos y documentos, especialmente los de formato electrónico. Así, los datos y documentos deberán ser únicos, compartidos, accesibles, abiertos, georreferenciados, descritos, estructurados y con la apuntada información sobre la publicidad, todo ello conforme al esquema nacional de interoperabilidad y sus normas técnicas de desarrollo en aquellos aspectos que resulte de aplicación y, en particular, para la selección de los formatos a utilizar y para los intercambios de información con otras organizaciones" (art. 7 OTLAI).

30 De la controversia doctrinal sobre la cuestión, ante la indeterminación legal sobre la misma, da cuenta BLANES CLIMENT, 2014: 342347 , que se inclina por admitir el acceso a la información conclusa obrante en procedimientos en tramitación. También crítico con la escasa precisión legal se muestra FERNÁNDEZ RAMOS, 2013: 236-237. Es más, el propio FERNÁNDEZ RAMOS, con PÉREZ MONGUIÓ, 2014: 159, afirma que la previsión de artículo 15.3 de la Ley 4/2013, de 21 de mayo, de Gobierno Abierto de Extremadura, conforme al cual "tendrán la consideración de información pública de libre acceso para cualquier ciudadano, sin que precisa ostentar la condición de interesado, los expedientes administrativos que estén concluidos", debe interpretarse como no excluyente de la noción de información pública de los expedientes administrativos en trámite.

31 La jurisprudencia se ha pronunciado sobre esta cuestión en relación con el acceso a la información ambiental en la Sentencias 3 de octubre de 2006 (casación 2424/2003), 4 de abril de 2006 (casación 311/2003), 17 de febrero de 2004 (casación 3457/2000) y 28 de octubre de 2003 (casación 3928/1999) del Tribunal Supremo de 29 de septiembre de 2011 (casación 2071/2008), afirmando en la última que "no se puede confundir -como pretende la Administración recurrente- un "informe inconcluso" -es decir en fase de borrador, pendiente todavía por ejemplo de firma por su autor, o de su preceptiva conformidad por el jefe de la unidad técnica correspondiente- con un "expediente inconcluso" en el que figuran sucesivos informes -todos ellos "conclusos"- a los que se podrán ir añadiendo nuevos datos o resultados de distinto signo conforme avancen las distintas fases del procedimiento administrativo. En este segundo supuesto de "expediente inconcluso" o inacabado, porque todavía carece de resolución final de archivo, los documentos a él incorporados -como son, en el caso que examinamos, los informes de auscultación del embalse ya emitidos, solicitados por el Sr. Norberto ; o el "Programa de Puesta en Carga" expedido en la fase de llenado de la presa requerido por el Ayuntamiento de Longuida- son documentos evidentemente conclusos, aunque el procedimiento administrativo todavía no haya finalizado y no se excluya la posibilidad de que se emitan luego otros informes conforme a los nuevos datos que, en su caso, vayan apareciendo durante la ejecución del proyecto". Como se afirmó ya en la primera de las sentencias citadas, la de 3 de octubre de 2006, que "Interpretadas correctamente la Directiva y la Ley citadas, e interpretado correctamente el artículo 3.3 de una y otra, debió facilitarse 
Frente al silencio de la LTAIPBG, así como de la OtTAIR, en línea con la anterior, resulta absolutamente explícita la previsión del artículo 6.3.b) OTLAl, que prevé, coherentemente con lo señalado, que "el acceso de los interesados a los documentos obrantes en los expedientes en tramitación queda fuera del ámbito objetivo de esta Ordenanza y, por tanto, no tendrá el carácter de publicación ni de puesta a disposición. Solo una vez terminados los procedimientos la información obrante en los expedientes tendrá carácter de pública, y podrá publicarse y ser puesta a disposición con la finalidad principal de dar a conocer a la ciudadanía las decisiones municipales y los criterios que las rigen". La exclusión de los expedientes en curso del ámbito de aplicación de la ordenanza zaragozana la confirma la inclusión como causa de inadmisión de las solicitudes de puesta a disposición de las "que se refieran a información correspondiente a un procedimiento en tramitación, sin perjuicio del derecho reconocido a los interesados en los términos del artículo 35.a) de la Ley 30/1992, de 26 de noviembre, de régimen jurídico de las administraciones públicas y del procedimiento administrativo común". El artículo 26 OTLAl, por lo demás, obliga al Ayuntamiento a publicar aquellos documentos obrantes en expedientes terminados "que tengan notoria relevancia pública o que establezcan criterios de actuación para el Ayuntamiento". En cualquier caso, la propia transformación del objeto del derecho de acceso, que de proyectarse sobre documentos se refiere ahora a información, contenida en muy diversos soportes, determinará muy probablemente la forzada superación de planteamientos formalistas en línea con la posición ya expresada del Tribunal Supremo (BLANES, 2014: 259-265 o FERNÁNDEZ y PÉREZ, 2014: 154-162).

A continuación abordaré la articulación del derecho fundamental a la protección de datos con la transparencia y acceso público a la información, tanto en el contexto normativo previo a la LTAIPBG como en el resultante tras su completa entrada en vigor.

\section{La articulación del derecho fundamental a la protección de datos con la transparencia y acceso público a la información en la pionera Ordenanza de transparencia de Zaragoza}

Más atrás he puesto de manifiesto la importancia que la aprobación de la LTAIPBG ha tenido sobre el régimen jurídico de la transparencia administrativa y del acceso a la información pública. Estamos ante una norma básica llamada a ser desarrollada mediante la legislación autonómica y, en el ámbito local, mediante normas reglamentarias. En este nuevo contexto resulta fundamental la articulación general del derecho fundamental a la protección de datos con el principio de transparencia y el derecho de acceso a la información pública no sólo en el marco hoy vigente resultante de la propia LTAIPBG, que tras su completa entrada en vigor incorporará a nuestro ordenamiento jurídico un régimen jurídico totalmente renovado, suprimiendo la regulación del art. 37 LAP y sentando nuevos principios y reglas básicas mucho más favorables a la transparencia y al libre acceso a la información pública, sino también, para lograr su adecuada comprensión, del anterior, conformado en lo esencial por la normativa de protección de datos y los artículos 35 y 37 LAP ${ }^{32}$. Al tratarse de la primera Ordenanza de transparencia aprobada tras la LTAIPBG, resulta de interés analizar el régimen propuesto por la OTLAI, sustancialmente modificado en este punto de la aprobación inicial a la definitiva ${ }^{33}$.

A) La primera propuesta de articulación entre transparencia y protección de datos en 2013 en el marco normativo anterior a la Ley de Transparencia.

La OTLAI inicialmente aprobada en 2013 dedicó a la cuestión de la protección de datos de carácter personal su artículo 10, integrado en el capítulo II de su título II, sobre limitaciones a la publicidad. En él podía constatarse la obvia colisión entre derecho a la protección de los datos personales y transparencia y la imperiosa necesidad de articularlos de manera adecuada. Redactado mucho antes de la aprobación de la LTAIPBG, establecía dicho precepto en primer lugar el carácter de fuentes accesibles al público de determinada información sobre cargos y empleados del Ayuntamiento en el marco establecido en el artículo 3.j) LOPD lo que, por ello, hacía innecesaria, aunque resultase aclaratoria, la regulación propuesta (art. 10.1). Precisaba también el carácter público de la información sobre retribuciones de cargos electos municipales, de los demás órganos superiores y directivos, de los responsables de las sociedades y fundaciones y de los demás empleados municipales o de dichas entidades, bien

información de los documentos obrantes en los expedientes que, (1) siendo separables, (2) estuvieran -ellos, los documentos- conclusos ". En sentido similar, en relación con acceso a documentos obrantes en instituciones europeas, Sentencias del Tribunal General de la Unión Europea de 22 de marzo y 7 de junio de 2011 (asuntos T-233/09 y T-471/08 respectivamente), la primera confirmada tras desestimar el recurso de casación por la Sentencia del Tribunal de Justicia de la Unión Europea de 17 de octubre de 2013 (asunto C-280/11 P).

32 Vigente transitoriamente conforme a la disposición final novena LTAIPBG.

33 El borrador inicial data de 25 de junio de 2012. Fue sometido a un proceso de participación cuyos resultados culminaron el 5 de diciembre de 2012, fecha en que fueron informadas las aportaciones por los servicios municipales. Un primer texto fue objeto de aprobación inicial recayó el 14 de marzo de 2013. Posteriormente recayó nueva aprobación inicial el 31 de enero de 2014, quedando definitivamente aprobada el 1 de abril de 2014. Puede accederse en el enlace https://www.zaragoza.es/ciudad/normativa/detalle_Normativa?id=3983 (consultado a 23 de octubre de 2014). 
es cierto que, en relación con estos últimos la información se referirá a las categorías profesionales y puestos pero no se vinculará a personas concretas, de modo que, disociada de personas físicas, ninguna objeción puede hacerse desde la perspectiva de la protección de datos, según ha quedado ya explicado (art. 10.2).

Mayor interés y complejidad tenía el apartado tercero del artículo 10 OTLAI inicialmente aprobada en 2013, precepto de importancia capital en el sistema de la OTLAI y para su articulación con la normativa de protección de datos vigente actualmente ${ }^{34}$. Son muy diversas cuestiones las que abordaba este precepto. Vaya por delante que, en lo esencial, trataba de coordinar la amplia definición de información pública con la imperativa protección de datos personales exigible, conforme a otras normas, de acuerdo con la LOPD. Recuérdese que "es información pública del Ayuntamiento de Zaragoza toda aquella que obre en su poder y que haya sido elaborada o adquirida en el ejercicio de sus funciones. Esta información podrá estar en soporte papel o en formato electrónico y, en este segundo caso, tener la forma de datos o de documentos electrónicos" (art. 6.1 OTLAI, en versión de 2013). Sobre tal base, la OTLAI aprobada inicialmente en 2013 distinguía dentro de la información pública la vinculada a la transparencia y la vinculada a la prestación de servicios y a la gestión de sus recursos, que se someterían a la OTLAI, de la información obrante en los expedientes administrativos, que sólo se sometería a la OTLAI cuando los procedimientos hubiesen concluido, quedando el acceso de los interesados a los expedientes en tramitación fuera del ámbito de la ordenanza (art. 6.3 OTLAI). Tan amplia definición se reforzaba, además, con la presunción del carácter público de la información obrante en la Administración municipal, que determinaba que sólo podía denegarse el acceso a la misma en los supuestos expresamente previstos en las Leyes o en la propia Ordenanza y mediante resolución motivada (art. 3.1 OTLAI). Esta presunción encontraría hoy cobertura en el artículo 13 LTAIPBG, que prevé que "se entiende por información pública los contenidos o documentos, cualquiera que sea su formato o soporte, que obren en poder de los sujetos incluidos en el ámbito de aplicación de este título y que hayan sido elaborados o adquiridos en el ejercicio de sus funciones".

Resultando innegable la existencia de fichero y de tratamiento, la amplia definición de la información pública, el extenso ámbito de la publicidad activa (arts. 3.2 y 18 a 29) y la presencia de multitud de datos personales en dicha información era obvia la necesaria observancia de la normativa de protección de datos, máxime en un contexto como el vigente en 2013 en el cual todavía no existía normativa legal de transparencia y libre acceso a la información que pudiese operar como ley especial de la LOPD, en el sentido que ha quedado expuesto más atrás, modulando las rigurosas exigencias de información y consentimiento para el tratamiento establecidas en ésta. Sobre la base de un criterio subjetivo, la propuesta de ordenanza zaragozana de 2013, tras regular la publicidad de la información de personas físicas integradas bajo diferentes formas jurídicas en la estructura municipal, entendida en el sentido del artículo 2 OTLAI, abordaba la cuestión de la publicidad de la información relativa a "personas no pertenecientes al Ayuntamiento" distinguiendo tres supuestos.

El primero de tales supuestos era el de aquella información que incorporase datos personales relativa a personas no pertenecientes al Ayuntamiento cuando se refiera a una relación económica con el mismo, en la que estas actúen en su calidad de profesionales, de empresarios individuales o de directivos o miembros de los órganos de gobierno de una persona jurídica. La publicación se amparaba en las excepciones a la prestación de consentimiento para el tratamiento establecidas con carácter general cuando los datos de carácter personal se recojan para el ejercicio de las funciones propias de las Administraciones públicas en el ámbito de sus competencias o se refieran a las partes de un contrato o precontrato de una relación negocial, laboral o administrativa y sean necesarios para su mantenimiento o cumplimiento" (art. 6.2 LOPD). En segundo lugar se regulaba la información que incorporase datos personales de personas físicas en su condición de administrados que no pertenezcan a las categorías de datos especialmente protegidos definidas en la LOPD. Podía ser objeto de publicación si existe un interés público preferente que lo justifique, previsión que se incardina de nuevo en las excepciones a la prestación de consentimiento previo y, en concreto, a la que autorizaba el tratamiento cuando fuese necesario para la satisfacción del interés legítimo perseguido por el responsable del fichero o por el del tercero a quien se comuniquen los datos, siempre que no se vulneren los derechos y libertades fundamentales del interesado, teniendo presente el efecto directo del artículo 7.f) de la Directiva 95/46/CE en la interpretación que realizó la Sentencia del Tribunal de Justicia de la Unión Europea de 24 de noviembre de 2011. Finalmente, en tercer lugar, se recogía aquella información que incorporase datos personales de personas físicas en su condición de administrados que perteneciesen a las

34 El texto aprobado inicialmente en 2013 preveía lo siguiente: “3. También podrá publicarse la información relativa a personas no pertenecientes al Ayuntamiento cuando se refiera a una relación económica con el mismo, en la que estas actúen en su calidad de profesionales, de empresarios individuales o de directivos o miembros de los órganos de gobierno de una persona jurídica. Cuando los datos se refieran a su situación de administrados y siempre que no pertenezcan a la categorías de datos especialmente protegidos definidas en la Ley Orgánica 15/1999, de 13 de diciembre, de protección de datos de carácter personal, podrán ser objeto de publicación si existe un interés público preferente que lo justifique. En el resto de los casos, los datos y documentos que contengan datos personales se publicarán o pondrán a disposición previo proceso de disociación". 
categorías de datos especialmente protegidos definidas en la LOPD. Los documentos que contuviesen estos datos sólo podían publicarse cumpliendo las exigencias de consentimiento y en los supuestos establecidos en la LOPD.

En su último inciso el mismo precepto incorporaba una cláusula de cierre para "el resto de los casos", es decir, en relación con cualquier información que incorporase datos personales no susceptibles de publicación conforme a los criterios anteriores, por no existir interés público prevalente o consentimiento cuando resultase exigible. En estos supuestos "los datos y documentos que contengan datos personales se publicarán o pondrán a disposición previo proceso de disociación”, es decir, desvinculándolos de personas físicas determinables y, de ese modo, sin sujeción a la normativa de protección de datos, tal cual establece ella misma, posibilidad que resulta plenamente coherente con la LOPD y su normativa de desarrollo.

Lejos de encontrar una habilitación para la publicación de la información administrativa y el libre acceso a la misma en lo establecido en los artículos 35.h) y 37 LAP, y aun dejando al margen los regulados en otras normas especiales (sobre todo, por su amplio ámbito de aplicación el del artículo 28 del Real Decreto 1708/2011, de 18 de noviembre, por el que se establece el sistema español de archivos y se regula el sistemas de archivos de la administración general del Estado y su régimen de acceso), en los mismos hallábamos más bien obstáculos a la pretendida difusión de la información. Recuérdese a este respecto que los citados preceptos otorgaban un derecho de acceso a los registros y los documentos que, formando parte de un expediente correspondiente a un procedimiento terminado, obrasen en los archivos administrativos. Pero en modo alguno reconocían ese derecho con carácter general, sino que lo limitaban tanto desde una perspectiva subjetiva como objetiva. Así, cuando los documentos contenían datos referentes a la intimidad de las personas sólo sus titulares podían acceder, mientras que cuando tenían carácter nominativo sin incluir tales datos relativos a la intimidad, entre otras exigencias, podían acceder únicamente quienes acreditasen un interés legítimo y directo, reglas del todo incompatibles con las habituales en las normas sobre transparencia.

No es complicado deducir las dificultades que, vigente tal normativa básica, podían oponerse a una regulación reglamentaria como la municipal expuesta que trataba de ampliar tanto la publicidad activa como la puesta a disposición "sin necesidad de alegar ningún motivo ni de indicar la finalidad del acceso" (art. 30.1 OTLAI). Téngase en cuenta, además, que el régimen de acceso de los artículos 35.h) y 37 LAP estaba subordinado también a las garantías del derecho fundamental a la protección de datos establecidas en la LOPD y sus disposiciones de desarrollo, como puso de manifiesto en numerosas ocasiones la Agencia Española de Protección de Datos ${ }^{35}$.

B) La adecuación de la propuesta de 2013 a la Ley de Transparencia y su sustancial modificación en la ordenanza finalmente aprobada.

Tampoco resultaba posible acreditar la compatibilidad del régimen expuesto que se propuso en 2013 con la LTAIPBG pese a establecer esta un régimen mucho más favorable a la publicidad activa y el acceso a la información pública eliminando las rigideces de los artículos 35.h) y 37 LAP, que pasaron a remitir íntegramente a la nueva norma legal. Con la LTAIPBG vendría a superarse una situación, puesta de manifiesto por la doctrina y las autoridades administrativas de protección de datos, conforme a la cual ni la normativa de protección de datos ni la normativa de régimen jurídico reguladora del acceso a documentos administrativos facilitaban la difusión pública y el libre acceso a la información administrativa ${ }^{36}$. De ahí la importancia del nuevo régimen de acceso establecido en la LTAIPBG, que será la norma habilitante tan reclamada por los estudiosos de la transparencia37. Resulta harto sorprendente, y fue merecedor de crítica en el Dictamen 707/2012, de 19 de julio, sobre el anteproyecto de Ley de transparencia, acceso a la información pública y buen gobierno, que aunque la LTAIPBG se imponga sobre la restrictiva normativa básica de régimen jurídico al modificar los artículos 35.h) y 37 LAP, se subordine a los regímenes previstos en normas especiales, a cuyas normas reguladoras remite su disposición adicional primera, que ni se modifican ni se derogan, al carecer la LTAIPBG, además, de disposición derogatoria. Esa remisión a normativa específica podrá determinar regímenes de publicidad y acceso más restrictivos o más favorables, si bien habrá de

35 Por todos, Informes de 22 de marzo de 2000, 25 de octubre de 2011 y 5 de junio de 2012.

36 Como puso de manifiesto la extensa Recomendación 2/2008, de 25 de abril, de la Agencia de Protección de Datos de la Comunidad de Madrid, sobre publicación de datos personales en boletines y diarios oficiales en Internet, en sitios webs institucionales y en otros medios electrónicos y telemáticos (BOCM n. ${ }^{\circ} 214$, de 8 de septiembre de 2008) "no existe una habilitación legal clara que permita la cesión de datos personales sin un interés legítimo y sin consentimiento del interesado en beneficio del principio de transparencia administrativa" porque "la LOPD no contempló como límite al derecho fundamental a la protección de datos personales un derecho de acceso a información administrativa sin interés legítimo ni previó una publicación generalizada de información administrativa con datos personales a instancia de la Administración" (apartado II de la exposición inicial, párrafo tercero). Sobre esta cuestión vid. los trabajos incluidos en el volumen colectivo A. TRONCOSO REIGADA (Dir.), Transparencia administrativa y protección de datos personales, Civitas y APDCM, Madrid, 2008.

37 GUICHOT, 2005: 256-269; TRONCOSO, 2008: 48-57; y, ya tras la LTAIPBG, FERNÁNDEZ y PÉREZ, 2014: $183-184$. 
completarse en todo caso con el antes apuntado carácter de norma de mínimos que tiene la LTAIPBG al menos en lo que respecta a la publicidad (art. 5.2) $)^{38}$.

De cara al futuro, y a la valoración de las normas locales sobre transparencia, es esencial la coordinación de la LTAIPBG con la normativa de protección de datos, que se modificó notablemente tras el Informe de la Agencia Española de Protección de Datos de 5 de junio de 2012 y Dictamen del Consejo de Estado 707/2012, de 19 de julio de 2012. El Consejo de Estado advirtió con claridad y contundencia que "el anteproyecto se fundamenta en la excepción a la necesidad del consentimiento de los titulares de los datos prevista en el artículo 11.2.a) de la Ley Orgánica 15/1999, de 13 de diciembre, de protección de datos de carácter personal (LOPD). [... ] Desde esta perspectiva adquiere su cabal sentido la regla con la que se inicia el artículo 11.1 del anteproyecto, según la cual «cuando la solicitud de acceso se refiera a información pública que contenga datos de carácter personal se aplicarán las disposiciones previstas en esta Ley». [... ] Las anteriores reflexiones revelan, en cualquier caso, la especialidad del anteproyecto desde la perspectiva de la protección de datos de carácter personal. Y ello por cuanto de ordinario, los supuestos que se ampara en la cláusula del artículo 11.2.a) de la LOPD suelen presentar un carácter marcadamente sectorial [...] o especial [...] en tanto que el anteproyecto posee una proyección general y sumamente amplia, que le lleva a introducir mecanismos específicos de ponderación de los derechos de los titulares de esos datos que pueden obrar en la correspondiente información pública” [apartado V.g) Del Dictamen 707/2012].

Tal es, precisamente, el sentido y el encaje del nuevo régimen jurídico de publicidad activa y libre acceso a la información pública que establece, fundamentalmente, el artículo 15 LTAIPBG, profundamente modificado en atención a las consideraciones del Dictamen del Consejo de Estado 707/2012 y, muy especialmente, del Informe de 5 de junio de 2012 de la Agencia Española de Protección de Datos (apartados VII a XV). El objetivo fundamental de la nueva regulación, como precisó el Consejo de Estado, es establecer una regulación general y amplia en materia de transparencia, en su doble vertiente de publicidad activa y derecho de acceso a la información pública, similar a la que existe en la mayoría de los países de nuestro entorno (Dictamen 707/2012, III, cuarto párrafo). Tal carácter general y amplio es, a mi juicio, lo que hacía imperiosa la sustitución de la regulación de los artículos 35 .h) y 37 LAP por una remisión a la nueva norma y la articulación de ésta como norma especial en el marco de la LOPD, norma habilitante del tratamiento sin previo consentimiento en el marco autorizado por la normativa de protección de datos.

Desde esta perspectiva, el Proyecto de LTAIPBG partía de la regla general, que se eliminó durante la tramitación parlamentaria, consistente en que "cuando la solicitud de acceso se refiera a información pública que contenga datos de carácter personal se aplicarán las disposiciones previstas en esta Ley” (art. 15.1, primer inciso, del Proyecto), regla que debía matizarse, como hacía igualmente el Proyecto, cuando los datos que contuviese la información se refiriesen únicamente al solicitante, en cuyo caso imponía la aplicación de la normativa de protección de datos sin perjuicio de que, en estos supuestos y tal cual indicó la Agencia Española de Protección de Datos (apartado VIII del Informe de 5 de junio de 2012), el otorgamiento del acceso permitiese el conocimiento por el solicitante no sólo de los datos que contenga la información de los que sea titular, sino de ésta en su totalidad (art. 15.1, segundo inciso, del Proyecto). Resultó coherente la supresión de esta previsión del Proyecto, dado que realmente la LTAIPBG no excluye la aplicación ni sustituye a la LOPD sino que, rectius, opera como ley especial que, en el marco de sus previsiones flexibiliza el tratamiento y difusión de información en el marco del principio de transparencia.

Cuando los datos a los que se refiere la solicitud de información sean datos especialmente protegidos del artículo 7.2 LOPD, el acceso únicamente se podrá autorizar en caso de que se contase con el consentimiento expreso y por escrito del afectado, "a menos que dicho afectado hubiese hecho manifiestamente públicos los datos con anterioridad a que se solicitase el acceso" (art. 15.1, primer párrafo, LTAIPBG). Si la información incluyese datos especialmente protegidos del artículo 7.3 LOPD, o datos relativos a la comisión de infracciones penales o administrativas que no conllevasen la amonestación pública al infractor (art. 7.5 LTAIPBG), el acceso sólo se podrá autorizar en caso de que se cuente con el consentimiento expreso del afectado o si aquél estuviera amparado por una norma con rango de Ley (art. 15.1, segundo párrafo, LTAIPBG). De este modo, la LTAIPBG hace suya en estos casos, una vez más, las reglas establecidas en el artículo 7 LOPD en relación con datos especialmente protegidos LOPD,

38 Hubiera sido deseable más precisión, dados los derechos e intereses en presencia, pues, como afirmó el Consejo de Estado “no resulta sencillo determinar en todos los casos cuál es la norma de aplicación preferente, lo que permite albergar ciertas dudas en relación con el pretendido alcance general de la disposición proyectada y, por ende, con su efecto innovador en el ordenamiento jurídico. Esta posible colisión puede surgir de manera particularmente intensa en materia de subvenciones, publicidad de contratos del sector público o protección de datos de carácter personal, pudiendo, por lo demás, llegar incluso a plantearse en ciertos casos un verdadero conflicto entre el deber de secreto y confidencialidad que pesa sobre los empleados públicos y las normas sobre publicidad activa y derecho de acceso a información pública previstos en el anteproyecto" (apartado IV.2 del Dictamen 707/2012, que remite a diferentes puntos del apartado V). 
tal cual interesó la Agencia Española de Protección de Datos (apartado IX del informe de 5 de junio de 2012), bien es cierto que modulando su alcance en línea, en general, algo más favorable a la transparencia.

Por tanto, la LTAIPBG mantiene únicamente en relación con los datos especialmente protegidos la regla del consentimiento expreso, que además modula, según los casos, cuando el propio afectado no hubiese hecho manifiestamente públicos tales datos (los del art. 7.2 LOPD) o lo autorice una norma con rango de Ley (los del art. 7.3 LOPD). En relación con los datos personales no especialmente protegidos, la condición de la LTAIPBG de Ley especial, que en el marco de la LOPD exime de consentimiento previo al tratamiento y publicación de los datos, resulta mucho más contundente. El propósito de promover la transparencia, por tanto, resulta innegable y se erige así en auténtica idea fuerza inspiradora de la nueva regulación, como demuestra que en ella se prevea, expresamente, que "cuando la información solicitada no contuviera datos especialmente protegidos, el órgano al que se dirija la solicitud concederá el acceso previa ponderación suficientemente razonada del interés público en la divulgación de la información y los derechos de los afectados cuyos datos aparezcan en la información solicitada, en particular su derecho fundamental a la protección de datos de carácter personal” (art. 15.3 LTAIPBG). Ésta es la auténtica clave de bóveda de la nueva regulación, la ponderación del interés público en la divulgación de la información y los derechos de los afectados cuyos datos aparezcan en la información solicitada. Nos encontramos ante el quicio del sistema, enunciado y amparado claramente en la Sentencia del Tribunal de Justicia de la Unión Europea de 24 de noviembre de 2011 que, como se ha afirmado en varias ocasiones, declaró el efecto directo del artículo 7.f) de la Directiva 95/46/CE. Y todavía más claramente se desprende el propósito de la LTAIPBG de favorecer el acceso a la información al establecer que "con carácter general, y salvo que en el caso concreto prevalezca la protección de datos personales u otros derechos constitucionalmente protegidos sobre el interés público en la divulgación que lo impida, se concederá el acceso a información que contenga datos meramente identificativos relacionados con la organización, funcionamiento o actividad pública del órgano" (art. 15.2 LTAIPBG).

La Agencia Española de Protección de Datos, acertadamente, haciéndose eco de la Sentencia de 24 de noviembre de 2011 y con objeto de modular en el sentido expresado en la misma la discrecionalidad administrativa a la hora de realizar el juicio de ponderación al que se acaba de aludir, hizo especial hincapié en los apartados X a XIV del Informe de 5 de junio de 2012, en la necesidad de contar con suficientes criterios para afrontar tal ponderación, que no siempre conducirá a resultados claros. Es por ello que, con respecto al anteproyecto, la LTAIPBG introdujo un segundo inciso en el apartado tercero del artículo 15 que establece tales criterios ${ }^{39}$, sugeridos como he dicho por la propia Agencia, concretándolos en el menor perjuicio a los afectados derivado del transcurso de los plazos establecidos en el artículo 57 de la Ley 16/1985, de 25 de junio, del Patrimonio Histórico Español ${ }^{40}$, la justificación por los solicitantes de su petición en el ejercicio de un derecho o el hecho de que tengan la condición de investigadores y motiven el acceso en fines históricos, científicos o estadísticos. Este criterio proviene también de la normativa de patrimonio histórico español ${ }^{41}$, el menor perjuicio de los derechos de los afectados en caso de que los documentos únicamente contuviesen datos de carácter meramente identificativo de aquéllos y la mayor garantía de los derechos de los afectados en caso de que los datos contenidos en el documento puedan afectar a su intimidad o a su seguridad, o se refieran a menores de edad ${ }^{42}$.

39 Y, en conexión con el mismo, el régimen de acceso a documentos históricos regulado en el artículo 23 a 32 del Real Decreto 1708/2011, de 18 de noviembre, por el que se establece el sistema español de archivos y se regula el sistema de archivos de la Administración General del Estado y de sus organismos públicos y su régimen de acceso (objeto del Informe de 25 de octubre de 2011 de la Agencia Española de Protección de Datos). El artículo 57 de la Ley 16/1985 impide el acceso a los documentos que contengan datos personales de carácter policial, procesal, clínico o de cualquier otra índole que puedan afectar a la seguridad de las personas, a su honor, a la intimidad de su vida privada y familiar y a su propia imagen salvo que medie consentimiento expreso de los afectados o haya transcurrido un plazo de veinticinco años desde su muerte, si su fecha es conocida o, en otro caso, de cincuenta años, aun tratándose de personas vivas, según criterio de la Agencia Española de Protección de Datos, que ratifica el Reglamento, a partir de la fecha de los documentos. Lógicamente, el artículo 28 del Real Decreto 1708/2011 ratificó la regulación legal de la solicitud de consulta de documentos de acceso restringido por contener datos personales, sometiéndola a la normativa de protección de datos cuando se trate de datos del propio solicitante y previendo la regla legal del consentimiento previo para los demás casos, salvo que hayan transcurrido los plazos señalados, según los casos, desde el fallecimiento de las personas titulares de los datos o desde la fecha del documento. Se establece asimismo como regla general la posibilidad de acceso a documentos sujetos a procedimientos de disociación.

40 Sobre los mismos, analizando el citado precepto, MARTíNEZ, 2014: 266; FERNÁNDEZ y PÉREZ, 2014: 193-209; GUICHOT, 2014: 135140 .

41 Recuérdese que tanto el artículo 11.2.e) LOPD, limitándolo a cesiones entre administraciones públicas, como el artículo 28 del Real Decreto 1708/2011, sin tal limitación, otorgan acceso a documentos que contengan datos nominativos o meramente identificativos de las personas que no afecten a su seguridad o su intimidad a "quienes soliciten el acceso para el ejercicio de sus derechos y los investigadores que acrediten que el acceso se produce con una finalidad histórica, científica o estadística".

42 Si se tratase de datos especialmente protegidos recuérdese que no nos hallaríamos ante el supuesto de ponderación al que se refiere este criterio, pues el acceso requeriría consentimiento previo con las modulaciones establecidas en el artículo 15.2 LTAIPBG. 
Como he señalado anteriormente, la aplicación del régimen expuesto tiene como presupuesto la inclusión de los documentos y datos personales de que se trate dentro del ámbito protector de la normativa de protección de datos de carácter personal. Ello explica que, siguiendo lo establecido en el artículo 11.6 LOPD, y ampliándolo notablemente, se prevea ahora que "no será aplicable lo establecido en los apartados anteriores [del artículo 15 LTAIPBG] si el acceso se efectúa previa disociación de los datos de carácter personal de modo que se impida la identificación de las personas afectadas" (art. 15.5 LTAIPBG), regla que ha de ponerse en conexión con la estricta limitación de la publicidad activa en relación con documentos que contengan datos personales especialmente protegidos que, conforme al artículo 5.3 LTAIPBG, cuya publicidad "sólo se llevará a cabo previa disociación de los mismos" (en este sentido véase el Informe de la Agencia Española de Protección de Datos de 5 de junio de 2012, $\mathrm{XVI}$ ). Esta previsión puede contribuir decisivamente a superar dificultades de gestión que la aplicación generalizada de la ponderación indudablemente puede llegar a generar dado el enorme volumen de datos y, potencialmente al menos, de peticiones de acceso pueden plantearse. Así, parece lógico prever que más allá de la información que haya sido objeto de publicidad activa, como regla general cuando se solicite el acceso a información pública esta se proporcionará disociada, ello sin perjuicio de que el órgano competente la proporcione íntegra previa ponderación. Todo lo anterior, por lo demás, no obsta a la previsión en la LTAIPBG de una serie de excepciones al acceso, que podrán determinar la inadmisión a trámite de las solicitudes, por razones diversas (art. 18 LTAIPBG).

En cualquier caso, de acuerdo con la nueva normativa básica, en los supuestos de publicidad activa o de libre acceso a la información pública, la normativa de protección de datos personales será de aplicación al tratamiento posterior de los obtenidos a través del ejercicio del derecho de acceso (art. 15.5 LTAIPBG), al igual que ocurrirá con la reguladora de la reutilización de datos públicos establecida en la Ley 37/2007, de 16 de noviembre, sobre reutilización de la información del sector público (en adelante LRISP) incorporó al ordenamiento español la Directiva 2003/98/CE, del Parlamento Europeo y del consejo, relativa a la reutilización de la información del sector público ${ }^{43}$. La norma es coherente con lo establecido en la normativa de protección de datos, que prevé que "aquel a quien se comuniquen los datos de carácter personal se obliga, por el solo hecho de la comunicación, a la observancia de las disposiciones de la presente Ley" (art. 11.5 LOPD). Ello no impide que el cedente continúe teniendo una serie de obligaciones formales en relación con los datos cedidos, como ocurre, por ejemplo, cuando resultando exigible y habiendo mediado consentimiento al tratamiento, "los datos rectificados o cancelados hubieran sido comunicados previamente, [pues] el responsable del tratamiento deberá notificar la rectificación o cancelación efectuada a quien se hayan comunicado, en el caso de que se mantenga el tratamiento por este último, que deberá también proceder a la cancelación" (art. 16.3 LOPD y 17.4 RPD). Pero no por ello el cedente resultará responsable del uso de los datos cedidos conforme a Derecho por parte del cesionario.

En el contexto normativo resultante de la LTAIPBG encaja perfectamente el régimen de transparencia establecido en la OTLAI, que se beneficia plenamente del impulso que proporciona el nuevo texto legal a la transparencia administrativa, modulando del modo expuesto la aplicación de la normativa de protección de datos y eliminando la restrictiva regulación en la LAP del derecho de acceso. En todo caso, conviene advertir de la notable carga de gestión que la aplicación del régimen de publicidad activa y libre acceso a la información generará cuando menos en el periodo de transición hacia un sistema de gestión transparente, que impone un tratamiento de los documentos que integran la información pública para hacer efectivas las limitaciones a la publicidad, el régimen de protección de datos personales y, cuando proceda, facilitar el juicio de ponderación determinante de la posibilidad de acceso que deberá realizar el órgano competente. No es tarea fácil, ni sencilla, aunque su progresiva implanta-

43 Criticada, con razón, por FERNÁNDEZ y PÉREZ, 2014: 31, por ser aprobada sin la simultánea garantía del acceso a la información pública, que constituye su presupuesto. El objeto de ambas normas es regular la reutilización de los documentos elaborados o custodiados por las Administraciones y organismos del sector público para llevar a cabo la misión de servicio público con fines comerciales o no comerciales y siempre que dicho uso no constituya una actividad administrativa pública (arts. 1 y 3.1 LRISP). Ahora bien, como se advierte en el mismo pórtico de la LRISP, su aplicación tendrá lugar "sin perjuicio del régimen aplicable al derecho de acceso a los documentos y a las especialidades previstas en su normativa reguladora" [art. 1, segundo inciso, y, en conexión con el mismo, 3.3.a) LRISP]. No obstante, el régimen de reutilización establecido en la LRISP no limita las previsiones más favorables que sobre acceso o reutilización se establezcan en las leyes sectoriales (art. 3.4 LRISP, conforme al art. 1.4 de la Directiva 2003/98/CE). Alguna reflexión merece la delimitación de su ámbito de aplicación. Desde la perspectiva subjetiva, acaso en base a interpretaciones análogas a las ya superadas en el ámbito de la contratación del sector público, la restrictiva incorporación a nuestro ordenamiento del concepto de “organismo de derecho público" de la Directiva, debe interpretarse, a mi juicio, de acuerdo con ésta, de modo que nada justifica, y menos aún tras la LTAIPBG, la exclusión de sociedades mercantiles de titularidad pública o participadas mayoritariamente por entes públicos, tal cual han hecho, por cierto, los arts. 12.1 y 2.1 OTLAl, siempre y cuando concurran en ellas los requisitos establecidos en los arts. 2.2 de la Directiva 2003/98/CE y 3 LRISP. Por otra parte, Directiva y LRISP plantean una importante salvedad al delimitar su ámbito objetivo, concretando los documentos que abarcan y al igual que ocurre en la normativa de transparencia, en relación con los documentos que contengan datos de carácter personal. Su reutilización se rige, según establece expresamente el artículo 4.6 LRISP, por lo dispuesto en la normativa de protección de datos de carácter personal. De este modo, parece reconocerse la primacía de esta última normativa sobre la de reutilización. Dicho de otro modo, la reutilización de documentos amparada por la LRISP nunca podrá ejercerse sin observar estrictamente las exigencias impuestas por la normativa de protección de datos. 
ción, y la normalización de procedimientos y estándares, conforme a los esquemas nacionales, simplificará con el tiempo estas tareas. La previsión como regla general del acceso disociado a información que no haya sido objeto de publicidad activa puede contribuir a mitigar la carga de gestión del nuevo sistema de transparencia, sin llegar a impedir, lógicamente, la posibilidad de acceso íntegro mediante la correspondiente ponderación en los términos previstos en la LTAIPBG y la propia OTLAI.

Atendiendo a lo anterior, el tan repetido artículo 10 OTLAI se modificó sustancialmente mediante el acuerdo de aprobación inicial de 2014 que fue, finalmente, el aprobado definitivamente. El principio general, coherente con la presunción del carácter público de la información administrativa, es conforme al texto vigente que "cuando la información pública contenga datos de carácter personal, se publicará o será accesible si existe un interés público preferente en tal publicación o acceso" (art. 10.1 OTLAI). Eso sí, tal regla cede en un supuesto. Los datos personales especialmente protegidos definidos en los apartados 2 y 3 del artículo 7 LOPD, únicamente podrán ser publicados o puestos a disposición en los términos y condiciones establecidos en tales preceptos (art. 10.4 OTLAI), previsión que, razonablemente, ha de ponerse en conexión con lo establecido en el artículo 15.1 LTAIPBG que, en lo esencial, remiten a la normativa de protección de datos.

Pero con carácter general la OTLAI impone el juicio de ponderación para determinar el interés prevalente a la hora de someter la información de que se trate a publicidad activa, considerando cuantos elementos y circunstancias concurran, si bien ha quedado establecida la presunción de existencia del interés público prevalente y determinante de la divulgación respecto de la información referida a los cargos electos y empleados del Ayuntamiento que esté directamente relacionada con la organización, el funcionamiento y las actividades del mismo, incluidos el nombre, cargo o función, órgano de pertenencia o unidad administrativa de destino, títulos académicos exigidos para el ejercicio de su función, forma de acceso al puesto y dirección profesional; la agenda de los cargos electos municipales; la remuneración percibida por los cargos electos municipales y los demás órganos superiores y directivos del Ayuntamiento en los términos del art. 38 del Reglamento Orgánico Municipal, así como por los responsables de las sociedades y fundaciones señalados en el art. 2 OTLAI, incluyéndose la totalidad de los ingresos y debiendo detallarse, en su caso, los distintos conceptos; las retribuciones de los empleados municipales y de los de las entidades a que se refiere el apartado anterior, referidas únicamente a las categorías profesionales y sin vincularse a personas concretas; $y$, finalmente, la relativa a personas no pertenecientes al Ayuntamiento que se refiera a una relación económica con el mismo, en la que éstas actúen en su calidad de profesionales, de empresarios individuales o de directivos o miembros de los órganos de gobierno de una persona jurídica (art. 10.2 OTLAI). Se suscita la duda acerca del carácter de la presunción que, a mi juicio, ha de considerarse iuris tantum, pues siempre existirá el juicio de ponderación y, aun cuando resulta difícil imaginar en muchos de los casos previstos circunstancias que determinen la no publicación de la información, no lo es tanto en otros, como el de la agenda de los cargos electos municipales, por ejemplo.

Regulado del modo expuesto el régimen de la publicidad activa, para la información no sujeta a publicidad activa, "la regla general será la publicación o puesta a disposición previa disociación de los datos de carácter personal que pudiera contener" (art. 10.3 OTLAI). Se opta así por un criterio pragmático, en el sentido que señalaba más atrás, anticipándose la normativa municipal mediante la disociación a posibles problemas desde la perspectiva de la normativa de protección de datos. Disociados éstos no se aplicará tal normativa.

\section{BIBLIOGRAFÍA}

L. A. BALLESTEROS MOFFA, La privacidad electrónica. Internet en el centro de protección, Tirant, Valencia, 2006.

J. L. BERMEJO LATRE y S. CASTEL GAYÁN, Transparencia, participación ciudadana y administración pública en el siglo XX, Monografías de la Revista aragonesa de Administración Pública, Zaragoza, 2013.

M. A. BLANES CLIMENT, La transparencia informativa de las administraciones públicas, Aranzadi, Pamplona, 2014.

L. COTINO HUESO, "El derecho fundamental de acceso a la información, la transparencia de los poderes públicos y el Gobierno Abierto. Retos y oportunidades", en el volumen colectivo J. VALERO TORRIJOS y M. FERNÁNDEZ SALMERÓN, Régimen jurídico de la transparencia del sector público. Del derecho de acceso a la reutilización de la información, Aranzadi, Pamplona, 2014, pp. 37-71.

S. FERNÁNDEZ RAMOS y JOSÉ MARÍA PÉREZ MONGUIÓ, Transparencia, acceso a la información pública y buen gobierno, Aranzadi, Pamplona, 2014. 
M. FERNÁNDEZ SALMERÓN, La protección de los datos personales en las Administraciones Públicas, Civitas, Madrid, 2003.

R. GARCÍA MACHO, "La transparencia en el sector público", en el volumen colectivo A. BLASCO ESTEVE (Coord.), El derecho público de la crisis económica. Transparencia y sector público. Hacia un nuevo derecho administrativo, INAP, Madrid, 2011, pp. 247-282.

- Derecho administrativo de la información y administración transparente, Marcial Pons, Madrid, 2010.

E. GUICHOT, Datos personales y Administración Pública, Civitas, Madrid, 2005.

- Publicidad y privacidad de la información administrativa, Civitas, Madrid, 2009.

- Transparencia y acceso a la información pública en España: análisis y propuestas legislativas, Fundación alternativas, documento de trabajo 170/2011.

- “Transparencia versus protección de datos”, en el volumen colectivo A. BLASCO ESTEVE (Coord.), El derecho público de la crisis económica. Transparencia y sector público. Hacia un nuevo derecho administrativo, INAP, Madrid, 2011, pp. 283-387.

E. GUICHOT (Coord.), Transparencia, acceso a la información pública y buen gobierno. Estudio de la Ley 19/2013, de 9 de diciembre, Tecnos, Madrid, 2014.

R. MARTÍNEZ, "De la opacidad a la casa de cristal. El conflicto entre privacidad y transparencia”, en el volumen colectivo J. VALERO TORRIJOS y M. FERNÁNDEZ SALMERÓN, Régimen jurídico de la transparencia del sector público. Del derecho de acceso a la reutilización de la información, Aranzadi, Pamplona, 2014, pp. 241-280.

A. MORETÓN TOQUERO (Coordinadora), Transparencia, acceso a la información pública y buen gobierno. Análisis de la cuestión tras la Ley 19/2013, monográfico de la Revista Jurídica de Castilla y León, mayo de 2014.

J. F. MUÑOZ SORO y J. L. BERMEJO LATRE, "La redefinición del ámbito objetivo de la transparencia y el derecho de acceso a la información pública", en el volumen colectivo J. VALERO TORRIJOS y M. FERNÁNDEZ SALMERÓN, Régimen jurídico de la transparencia del sector público. Del derecho de acceso a la reutilización de la información, Aranzadi, Pamplona, 2014, pp. 189-239.

R. PARADA VÁZQUEZ, Régimen jurídico de las Administraciones Públicas y del Procedimiento Administrativo Común (Estudio, comentarios y texto de la Ley 30/1992, de 26 de noviembre), 1993, Marcial Pons, Madrid.

L. POMED SÁNCHEZ, El derecho de acceso de los ciudadanos a los archivos y registros administrativos, INAP, Madrid, 1989.

- "El acceso a los archivos administrativos. El marco jurídico y la práctica administrativa", Revista de Administración Pública, n. 142 (1997), pp. 439-479.

J. L. PIÑAR MAÑAS, Seguridad, transparencia y protección de datos: el futuro de un necesario e incierto equilibrio, Fundación Alternativas, documento de trabajo 147/2009.

- “La necesidad de una Ley de transparencia”, en el volumen colectivo A. BLASCO ESTEVE (Coord.), El derecho público de la crisis económica. Transparencia y sector público. Hacia un nuevo derecho administrativo, INAP, Madrid, 2011, pp. 241-245.

C. RUÍZ-RICO RUÍZ, “Transparencia y participación en el derecho autonómico: un análisis constitucional”, Revista Internacional de Doctrina y Jurisprudencia, vol. 6, n. 1 (2014), http://www.ual.es/revistas/RevistalnternacionaldeDoctrinayJurisprudencia/pdfs/2014-06/articulos_transparencia-participacion.pdf (Consulta: 6 de octubre de 2014).

A. TRONCOSO REIGADA (Director), Transparencia administrativa y protección de datos personales, Civitas y APDCM, Madrid, 2008.

A. TRONCOSO REIGADA, "Transparencia administrativa y protección de datos personales", en el volumen colectivo dirigido por el mismo autor Transparencia administrativa y protección de datos personales, Civitas y APDCM, Madrid, 2008, pp. 23-188.

J. VALERO TORRIJOS y M. FERNÁNDEZ SALMERÓN, Régimen jurídico de la transparencia del sector público. Del derecho de acceso a la reutilización de la información, Aranzadi, Pamplona, 2014. 
C. VELASCO RICO, “Análisis en clave competencial del Proyecto de Ley estatal sobre transparencia, acceso a la información pública y buen gobierno”, en Revista d'Estudis Autonòmics i Federals, núm. 17, 2013, pp. $279-328$.

- "La cuestión competencial en la Ley 19/2013, de 9 de diciembre: ¿de qué margen disponen las CC.AA. en materia de transparencia, acceso a la información pública y buen gobierno?", en Transparencia, acceso a la información pública y buen gobierno. Análisis de la cuestión tras la Ley 19/2013, monográfico de la Revista Jurídica de Castilla y León, mayo de 2014. 